\title{
A Comprehensive Insight into Aldehyde Deformylation: Mechanistic Implications from Biology and Chemistry
}

DOI:

10.1039/D0OB02204G

Document Version

Accepted author manuscript

Link to publication record in Manchester Research Explorer

\section{Citation for published version (APA):}

Bagha, U. K., Satpathy, J. K., Mukherjee, G., Sastri, C., \& De Visser, S. (2020). A Comprehensive Insight into Aldehyde Deformylation: Mechanistic Implications from Biology and Chemistry. Organic \& biomolecular chemistry. https://doi.org/10.1039/D0OB02204G

\section{Published in:}

Organic \& biomolecular chemistry

\section{Citing this paper}

Please note that where the full-text provided on Manchester Research Explorer is the Author Accepted Manuscript or Proof version this may differ from the final Published version. If citing, it is advised that you check and use the publisher's definitive version.

\section{General rights}

Copyright and moral rights for the publications made accessible in the Research Explorer are retained by the authors and/or other copyright owners and it is a condition of accessing publications that users recognise and abide by the legal requirements associated with these rights.

\section{Takedown policy}

If you believe that this document breaches copyright please refer to the University of Manchester's Takedown Procedures [http://man.ac.uk/04Y6Bo] or contact uml.scholarlycommunications@manchester.ac.uk providing relevant details, so we can investigate your claim.

\section{OPEN ACCESS}




\title{
A Comprehensive Insight into Aldehyde Deformylation: Mechanistic Implications from Biology and Chemistry
}

Received 00th January 20xx, Accepted 00th January 20xx

DOI: $10.1039 / x 0 x x 00000 x$

\author{
Umesh Kumar Bagha, ${ }^{a}$ Jagnyesh Kumar Satpathy, ${ }^{a}$ Gourab Mukherjee, ${ }^{\text {a }}$ Chivukula V. Sastri, ${ }^{* a}$ and \\ Sam P. de Visser*b
}

\begin{abstract}
Aldehyde deformylation is an important reaction in biology, organic chemistry and inorganic chemistry and the process has been widely applied and utilized. For instance, in biology the aldehyde deformylation reaction has wide differences in biological function, whereby cyanobacteria convert aldehydes into alkanes or alkenes, which are used as natural products for, e.g., defense mechanisms. By contrast, the cytochromes P450 catalyse the biosynthesis of hormones, such as estrogen, through an aldehyde deformylation reaction step. In organic chemistry, the aldehyde deformylation reaction is a common process for replacing functional groups on a molecule, and as such, many different synthetic methods and procedures have been reported that involve an aldehyde deformylation step. In bioinorganic chemistry, a variety of metal(III)-peroxo complexes have been synthesized as biomimetic models and shown to react efficiently with aldehydes through deformylation reactions. This review paper provides an overview of the various aldehyde deformylation reactions in organic chemistry, biology and biomimetic model systems, which shows a broad range of different chemical reaction mechanisms for this process. Although a nucleophilic attack at the carbonyl centre is the consensus reaction mechanism, however, several examples of an alternative electrophilic reaction mechanism starting with hydrogen atom abstraction have been reported as well. There is still much to learn and to discover on aldehyde deformylation reactions, as deciphered in this review paper.
\end{abstract}

\section{Introduction}

Aldehyde deformylation is a fundamental reaction process in Organic Chemistry, which is inspired from analogous reactions in Nature. ${ }^{1}$ Thus, the aromatase enzyme is a cytochrome P450 (designated P450) isozyme in humans involved in the biosynthesis of hormones. In one of its reaction steps an aldehyde substituent on a cyclohexene ring is converted into an arene ring through a deformylation reaction to form estrogen. ${ }^{2-5}$ The aldehyde deformylation reaction has many applications in (bio)inorganic and organic chemistry, where a functional group is replaced through a desaturation reaction, Scheme 1. In general, the substrate loses formaldehyde and is desaturated through the reduction to an olefin or a ring structure. Over the years, many examples of aldehyde deformylation reactions have been reported. Despite the fact that the textbook reaction mechanism of aldehyde deformylation points to a nucleophilic pathway; actually recent studies suggested an alternative electrophilic proposal. In this review, we cover the various facets of aldehyde deformylation in Organic Synthesis, in Nature and in (Bio)Inorganic Chemistry, which shows diverse mechanistic features and processes. Our review will start with an overview of aldehyde deformylation

\footnotetext{
a. Department of Chemistry, Indian Institute of Technology Guwahati, Assam 781039, India.

E-mail: sastricv@iitg.ernet.in; Fax: +91-361-258-2349.

b. Manchester Institute of Biotechnology and the Department of Chemical

Engineering and Analytical Science, The University of Manchester, 131 Princess Street, Manchester M1 7DN, UK.

E-mail: sam.devisser@manchester.ac.uk
}

reactions in Biology with examples from the P450s and the aldehyde deformylating oxygenase (ADO). Subsequently, details of aldehyde deformylation in Organic Synthesis and (Bio)Inorganic Chemistry are discussed in later sections.

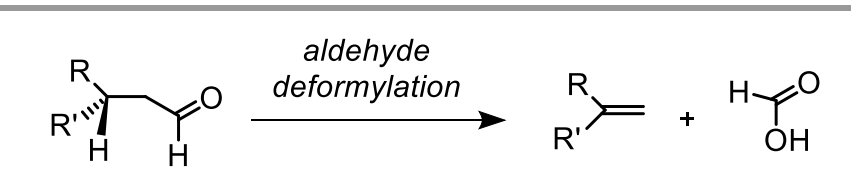

Scheme 1. General reaction mechanism for aldehyde deformylation.

\section{Aldehyde deformylation in biology}

Deformylation reactions are important processes in biology, as they lead to the shortening of the carbon chain of the substrate. For instance, the AlkB repair enzyme hydroxylates methylated DNA bases, which in a subsequent step undergo deformylation and return the base to their natural form. ${ }^{6,7}$ In biology, the cytochromes P450 can catalyse C $-\mathrm{C}$ bond cleavage reactions, including an aldehyde deformylation reaction. ${ }^{8-21}$ Similarly, aldehyde deformylation reactions are an important step in the biosynthesis of alkanes and alkenes in cyanobacteria. ${ }^{22-25}$

\subsection{Aldehyde deformylation by the P450s}

The cytochrome P450s are special enzymes, which belong to a superfamily of b-type hemoproteins found in most organisms. Their functions range from the metabolism and biodegradation of xenobiotics to the biosynthesis of natural products such as antibiotics and hormones. ${ }^{1-5,26-28}$ It is a family of heme 
containing monooxygenases with the primary function of the activation of dioxygen. In general, the P450s incorporate one oxygen atom of $\mathrm{O}_{2}$ into the substrate leading to aliphatic or aromatic hydroxylation or epoxidation products. The mechanisms of these oxygen-atom transfer reactions generally are stepwise via a radical intermediate as elucidated by computational studies. ${ }^{29-33}$ An unusual reaction catalysed by the P450s includes the oxidative deformylation of xenobiotic aldehydes with the introduction of the desaturation of a $\mathrm{C}-\mathrm{C}$ bond in the carbon framework. Aldehydes are the major component of odorants and are found in a wide variety of food products. ${ }^{14}$ One such aromatic aldehyde compound is citronellal, which is a lemon odored aldehyde used as a perfume in detergents as well as a flavouring compound in food. It is a $\beta$ branched aldehyde that undergoes an oxidative deformylation reaction by cytochrome $\mathrm{P} 450$ to form 2,6-dimethyl-1,5heptadiene. ${ }^{15}$ Cytochrome $\mathrm{P} 450$ enzymes also have been observed to catalyse the oxidative deformylation of cyclohexanecarboxaldehyde (CCA) to form hexene and formic acid. ${ }^{13}$ Little is known on the details of the reaction mechanism, but it has been proposed to involve a peroxy-hemiacetal-like adduct as an intermediate step. Further studies showed that a selection of aldehyde substrates was found to be activated, including isobutyraldehyde and trimethylacetaldehyde.

A specific $\mathrm{P} 450$ isozyme involved in the oxidative deformylation reaction to convert androgen to estrogen is aromatase. Aromatase is a microsomal cytochrome P450 enzyme, which reacts androgen with $3 \mathrm{~mol}$ of $\mathrm{NADPH}$ and $\mathrm{O}_{2}$ on a heme centre in a three-step oxidation pathway, Scheme $2 .{ }^{34,35}$ The first step constitutes the hydroxylation of the $\mathrm{C}_{19}$-position of the substrate using one molecule of $\mathrm{O}_{2}$ and NADPH. The second oxidation step results in the dehydrogenation of the alcohol group at $\mathrm{C}_{19}$ to an aldehyde using another molecule of $\mathrm{O}_{2}$, which then leads to the release of two water molecules. The final oxidation step is the oxidative deformylation that creates an arene ring and forms estrogen through the release of formaldehyde.
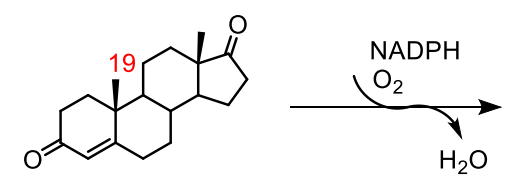

$\mathrm{H}_{2} \mathrm{O}$
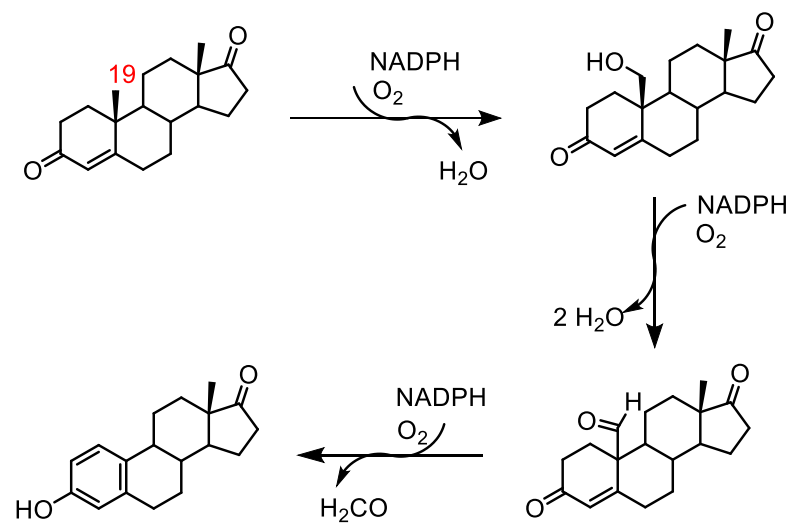

Scheme 2. Estrogen biosynthesis reactions catalysed by $\mathrm{P} 450$ aromatase enzymes.

The mechanism of aldehyde deformylation by aromatase enzymes for the catalysed conversion of androgen to estrogen was first explored by Korzekwa et al. ${ }^{16}$ The key intermediate responsible for the deformylation reaction was identified to be the iron(III)-peroxo heme complex. ${ }^{17-21}$ Experimental studies on the catalytic activity of aromatase enzymes appeared challenging due to the short lifetime of the intermediates during the catalytic cycle and active species formed in the reaction mechanism. Using a biomimetic iron(III)-peroxo(TPP) complex, TPP = tetraphenylporphyrin, Watanabe and co-workers confirmed the involvement of an iron-peroxo complex in the oxidative deformylation reaction catalysed by the P450s. ${ }^{36}$ In particular, cyclohexanecarboxaldehyde (CCA) was attacked by iron(III)-peroxo(TPP) complex in acetonitrile solvent under a helium atmosphere and gave cyclohexanone as a product through the condensation of $\mathrm{CCA}$ with $\mathrm{CH}_{3} \mathrm{CN}$, Scheme 3. In this reaction, the iron(III)-peroxo porphyrin complex acts as a nucleophile and attacks the aldehyde to form the corresponding deformylated products, although a significant amount of 3-cyclohexylacrylonitrile by-product originating from the condensation of CCA and acetonitrile was observed.
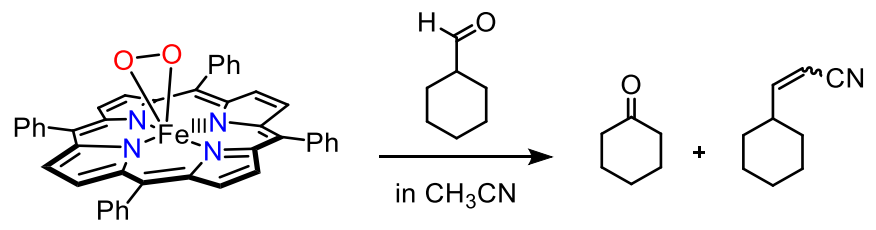

Scheme 3. Reaction mechanism of a biomimetic iron(III)-peroxo complex with cyclohexanecarboxaldehyde.

With the advance of computational modelling of metalloenzyme reaction mechanisms, ${ }^{37-41}$ several computational studies were performed on the details of the catalytic reaction mechanism of aromatase enzymes. Hackett and co-workers proposed the mechanism of cytochrome P450 catalysed deformylation of sterol-14 $\alpha$-demethylase (CYP51) from Mycobacterium tuberculosis using a combination of molecular dynamics simulations, density functional theory modelling (DFT) and hybrid quantum mechanics/molecular mechanics (QM/MM) methods. ${ }^{42,43}$ Scheme 4 displays the mechanism established from these modelling studies and how the catalytic cycle of the P450 monooxygenases diverts from the aldehyde deformylation pathway. Thus, the P450 catalytic cycle, generally, starts from a resting state, which has a water molecule ligated to the distal site of the heme, while the axial ligand is a cysteinate residue of the protein. ${ }^{1-5,26-28,37-39,44-48}$ Upon substrate binding, an electron transfer from its redox partner(s) is triggered that leads to dioxygen binding to the heme and a second reduction step then gives an iron(III)-peroxo intermediate. A proton-relay machinery in the P450 monooxygenases delivers two protons into the active site and converts the iron(III)-peroxo species into Compound I or the iron(IV)-oxo heme cation radical species. The latter was trapped and characterized for $\mathrm{P}^{450} \mathrm{C}_{\text {CAM }}$, a camphor hydroxylating P450 monooxygenase. ${ }^{49}$ 

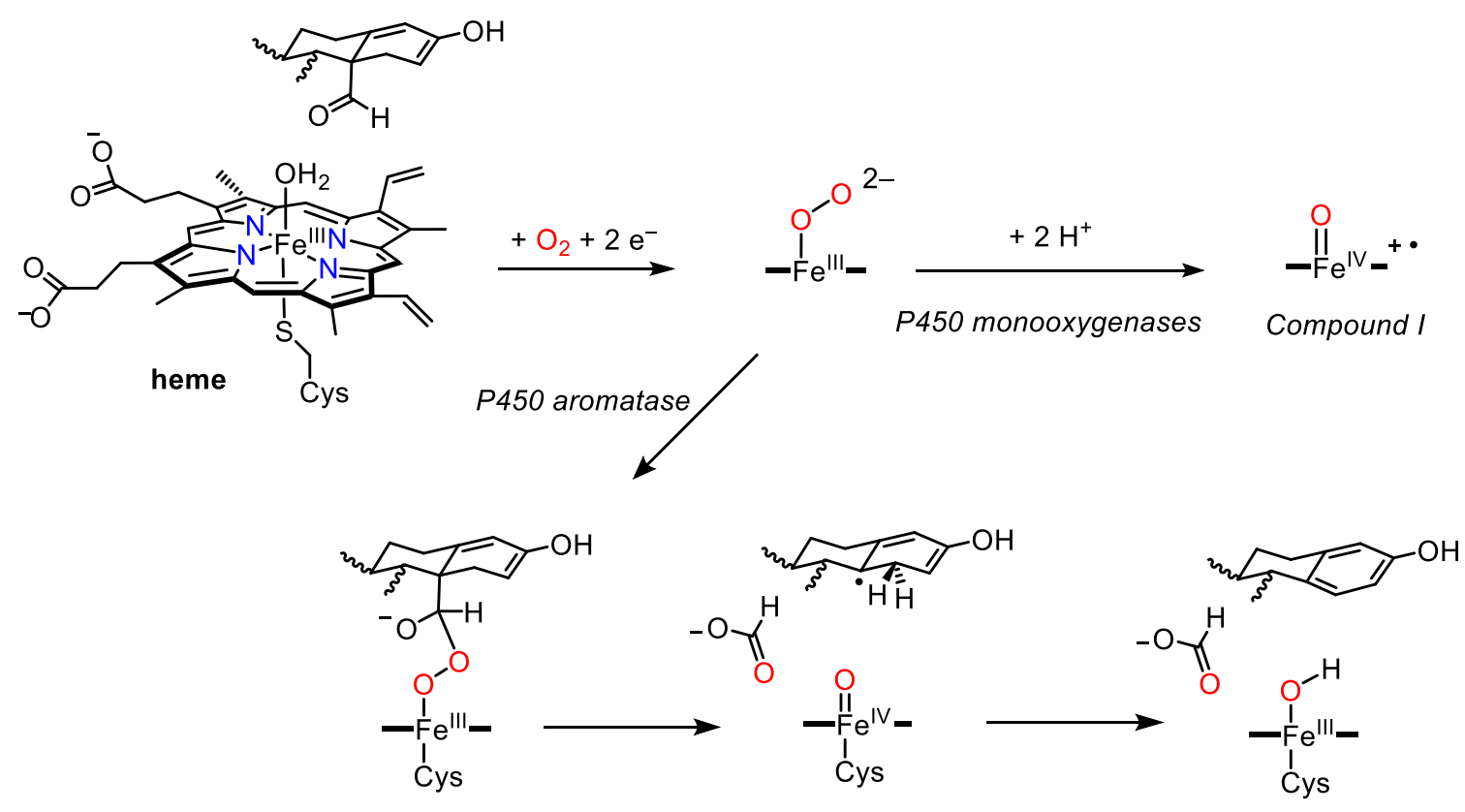

Compound II

Scheme 4. Computationally established mechanism of the deformylation step in the estrogen biosynthesis reaction by P450 aromatase.

By contrast to the P450 monooxygenases, in aromatase the proton-relay channels are blocked by the substrate and a direct reaction of the iron(III)-peroxo intermediate takes place as evidenced by molecular dynamics simulations. ${ }^{41}$ Interestingly, the P450 TxtE isozyme, which is a nitrating P450 structure that adds a nitrate group to aromatic substrates such as L-Trp, also has the proton-relay pathways blocked. In P450 TxtE the lack of a proton-relay mechanism was identified from differences in the active site of TxtE with respect to P450 monooxygenases. Thus, a comparison of the crystal structure coordinates of P450 TxtE and P450 CAM shows that key Glu and Asp residues in $\mathrm{P}^{4} 50_{\text {CAM }}$ involved in the proton-relay are missing from the TxtE structure. ${ }^{50}$ As a result of this, the P450 TxtE reacts with dioxygen, one proton and one electron to form an iron(III)superoxo species. It subsequently can reacts with NO generated by a nearby nitric oxide synthase enzyme to form iron(III)peroxynitrite as a precursor of a nitration reaction.

In P450 aromatase, the key intermediate in the reaction is believed to be the iron(III)-peroxo species and both proton relay steps are blocked. It reacts through a nucleophilic addition with the substrate aldehyde group to form a peroxo-hemiacetal intermediate (Scheme 4). Homolytic cleavage of the $\mathrm{C}-\mathrm{C}$ bond leads to the expulsion of formaldehyde and gives an iron(IV)oxo heme, i.e. Compound II. The latter abstracts a hydrogen atom from the substrate radical that is reduced to an aromatic ring and gives estrogen products. More recent computational studies showed that the disruption of the proton-relay channel by substrate positioning can lead to keto-enol tautomerization in ring $\mathrm{A}$ of androstenedione and converts the cyclohexanone group into an enol through proton transfer. ${ }^{51}$ Furthermore, the computational studies also showed that Compound I would be able to catalyse the deformylation and desaturation of the substrate to form estrogen. ${ }^{52}$ The question is, whether Compound I can be formed in the protein, but this question awaits an experimental study.

\subsection{Aldehyde deformylation by aldehyde deformylating oxygenase}

Aldehyde deformylation is one of the critical steps in the biosynthesis of alkanes and alkenes by cyanobacteria. As fatty alkanes and alkenes are the major components of fuels like gasoline, jet fuel, and diesel, 53,54 the biosynthesis of fatty alkanes/alkenes by cyanobacteria is considered to be an important process for developing renewable biofuels. ${ }^{55}$ For example, the $\mathrm{P} 450$ Ole $_{\mathrm{JE}}$ isozyme performs a decarboxylation of a fatty acid substrate to form terminal olefins. ${ }^{56-60}$ Computational studies; however, elucidated competing pathways leading to $\mathrm{C}^{\alpha}$-hydroxylation, $\mathrm{C}^{\beta}$-hydroxylation, desaturation and decarboxylation reaction channels. ${ }^{60-62}$ Other enzymes; however, react through aldehyde deformylation, such as the aldehyde decarbonylase enzyme (ADO). Thus, ADO converts fatty aldehydes into alkanes and $\mathrm{CO}$ by an oxidative deformylation reaction. ${ }^{63}$ Bollinger and co-workers, showed that the co-product from the aldehyde deformylation reaction is formate rather than $\mathrm{CO} .64,65$ 


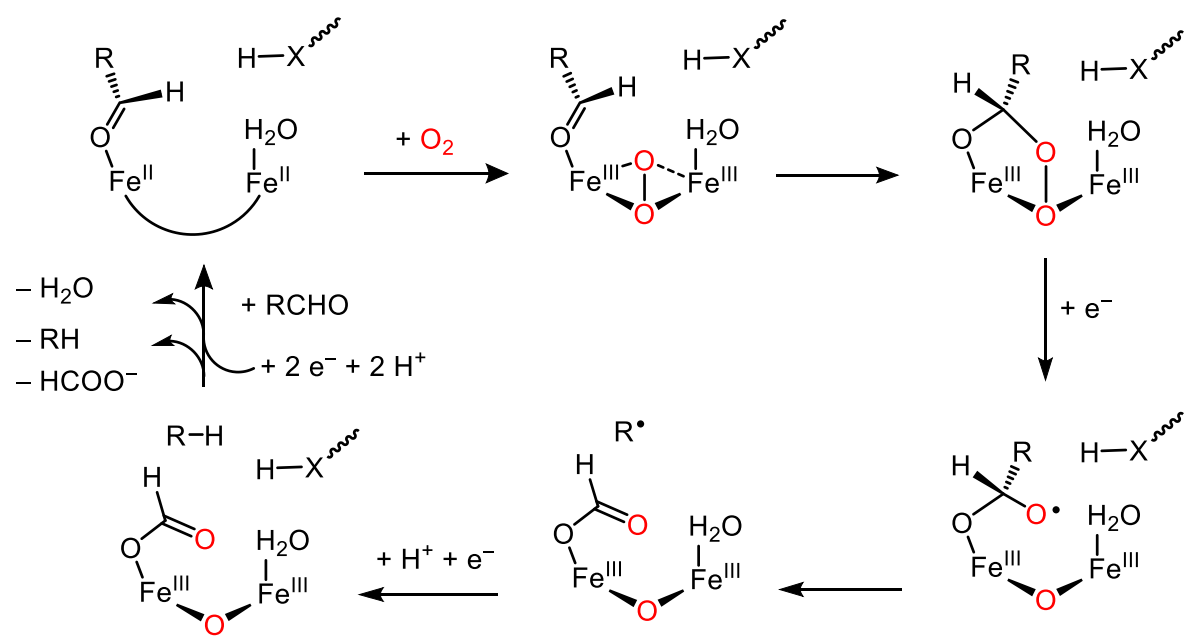

Scheme 5. Aldehyde deformylation reaction mechanism by the diiron enzyme ADO in the presence of an active site base $(H-X)$.

As a consequence, the enzyme aldehyde decarbonylase was renamed as the aldehyde deformylating oxygenase.

Cyanobacterial ADO, or CADO contains an oxygen bridged diiron cluster and belongs to a family of ferritin-like diiron proteins. ${ }^{64-70}$ An overview of the reaction mechanism of the aldehyde deformylating oxygenase is shown in Scheme 5 . The enzyme catalyses the conversion of linear $C_{n}$-fatty aldehydes into formate and the corresponding $\mathrm{C}_{n-1}$ alkenes. The reaction requires four electrons and one molecule of $\mathrm{O}_{2}$ per turnover which react to form one molecule of water, while the second oxygen atom of $\mathrm{O}_{2}$ is incorporated into the product as formate. ${ }^{71,72}$ The experimentally-derived mechanism is visually displayed in Scheme 5 and starts from a diiron enzyme that binds aldehyde (RCHO) on one of the iron(II) centres, while the other iron(II) centre holds a water molecule in its vacant ligand position. Dioxygen binding leads to the formation of a diiron(III)peroxo complex. ${ }^{64,65}$ Subsequently, one of the oxygen atoms of the peroxo group attacks the carbon atom of the aldehyde carbonyl group and forms a ring-structure. An electron transfer then cleaves the peroxo bond, which triggers homolytic $\mathrm{C}-\mathrm{C}$ bond breaking to form formate and an alkyl radical $\left(R^{\bullet}\right)$. Finally, a proton and electron transfer gives the alkane product $(\mathrm{RH})$ in a process that is assisted by the iron(III)-water group and an active site base ( $\mathrm{H}-\mathrm{X}$ group). When the product is released, the bridging oxo group is reduced to a water molecule through a reaction with two electrons and two protons. Evidence of this mechanism came from stopped-flow UV-Vis absorption, mass spectrometry and Mössbauer spectroscopic measurements that characterized a stable diiron(III)-peroxo intermediate. ${ }^{64,65}$ Electrochemical studies showed that for catalytic activity, ADO requires the donation of four external electrons, which can be generated from either a biological reduction partner (e.g., ferredoxin, Fd) or a chemical reducing system. ${ }^{72,73}$ It was shown that chemical reducing agents, such as phenazinemethosulfate, 1-methoxy-5-methylphenaziniummethylsulfate and $\mathrm{NADH}$ successfully activated ADO. ${ }^{72-75}$ Although the biological reducing system uses ferredoxin $(\mathrm{Fd})$ and ferredoxin-NADP ${ }^{+}$ reductase from spinach and NADPH, actually it was found that the chemical reducing system fared better and generated higher yields. ${ }^{73-75}$ More recently, Li and co-workers proposed that the cognate electron transfer system also support the ADO activity and supports greater activity as compared to the surrogate and chemical ones. ${ }^{75}$

The substrate scope was explored by Marsh et al who tested the reaction mechanism of ADO using a substrate having an oxirane ring attached adjacent to the aldehydic carbon. ${ }^{68}$ Deformylation of the substrate by ADO occurs to form the corresponding oxiranes rapidly. However, the product analysis showed that the alkanes obtained in the product are two carbon atoms shorter than the substrate, which indicated the formation of an oxaranyl radical through the rearrangement of the aldehyde. As such, a sequential two aldehyde deformylation reactions took place with this substrate. A crystal structure of palmitic acid bound diiron system of ADO was characterized, and an extract taken from the 4KVQ protein databank (pdb) file is shown in Fig. $1 .^{76,77}$ It has an $\alpha$-helical structure with four anti-parallel strands similar to ferritin. Both iron atoms are linked to the protein through a histidine interaction from $\mathrm{His}_{76}$ and $\mathrm{His}_{160}$. In addition, there are two terminal carboxylates bound to each iron atom $\left(\mathrm{Glu}_{45}\right.$ and $\left.\mathrm{Glu}_{128}\right)$ and two bridging carboxylate groups of $\mathrm{Glu}_{73}$ and $\mathrm{Glu}_{157}$. As such, the crystal structure of cADO suggests that it is a member of the non-heme diiron family of oxygenases that includes enzymes, such as methane monooxygenase, class I ribonucleotide reductase and fatty acyl carrier protein desaturase. ${ }^{78,79}$ 


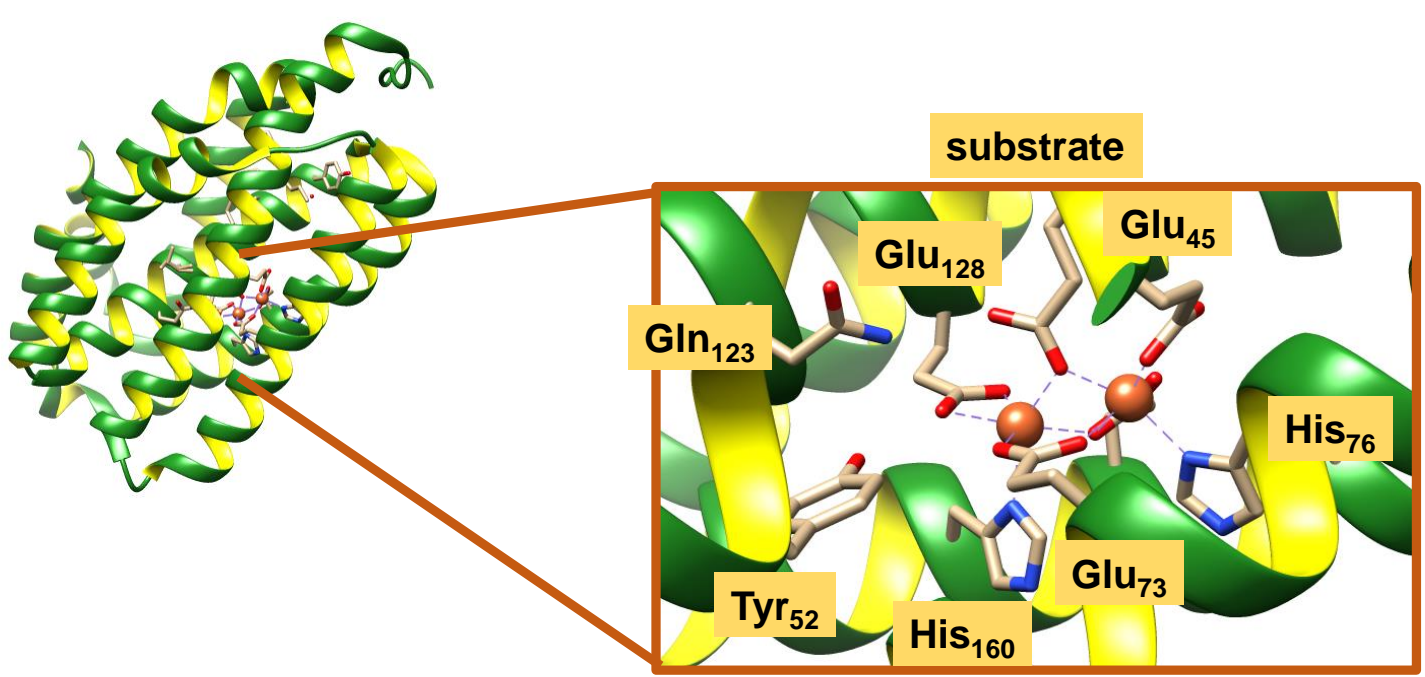

Fig. 1. Crystal structure of $A D O$ as taken from the $4 K V Q \mathrm{pdb}$ file with the diiron active site highlighted.

The active site of the enzyme contains an anti-parallel 4-helix bundle in which the two iron atoms are each coordinated by a histidine and two carboxylate ligands from the protein. Arai and co-workers investigated the roles of cysteine residues on the structure, stability and alkane producing activity of cyanobacterial ADO from Nostoc punctiforme PCC 731102 by systematic mutagenesis of Cys-to-Ala/Ser residues. ${ }^{80}$ The ADO structure contains three free cysteine residues at positions 71 , 107 and 117. The work showed that the $\mathrm{Cys}_{71}$ residue is in close proximity to the substrate-binding site and plays a key role in maintaining the activity, structure and stability of the enzyme. By contrast, mutations of $\mathrm{Cys}_{107}$ and $\mathrm{Cys}_{117}$ has little effect on the hydrocarbon production activity.

\section{Aldehyde deformylation in organic synthesis}

Natural products often have specific functional groups that give them their biological properties and function. Similarly, the introduction or removal of specific functional groups plays an essential part in Organic Chemistry. Furthermore, functional groups play a pivotal role in acting as directing groups that guide reactivity patterns and give the system a selectivity for a wide range of transformations. The formyl group is one of the key functional groups and is used extensively in organic synthesis. Yamada and co-workers have investigated the conversion of formyl groups into hydroxyl groups through a deformylative autoxidation of aliphatic aldehydes and the structural requirements in the substrate that favours the deformylative autoxidation of aldehydes. ${ }^{81}$ Carbohydrates, mainly $\alpha, \beta$ unsaturated sugars containing an unprotected hydroxy group at the $\mathrm{C}_{4}$-position were reacted selectively through deformylation with hydrazoic acid to give two stereoisomers by Michael-type addition (Scheme 6). ${ }^{82}$ The commercially available tri-O-acetylD-glucal is first converted to (2E,4S)-5-acetoxy-4-formyloxy-2pentenal. The reaction further proceeds via selective cleavage of formate ester on treatment with dilute ammonia leading to the deformylated $\alpha, \beta$-unsaturated aldehyde. The thus obtained deformlyated aldehyde is the key intermediate in the synthesis of various 3-substituted 2,3-dideoxypentoses.

Indolocarbazoles and their model systems perform a wide range of biological activities 83,84 and have attracted interest from synthetic and medicinal chemists. For instance, Pathak et al have synthesized naphtho[a]carbazoles and benzo[c]carbazoles through the deformylation of simple indole precursors. ${ }^{85}$
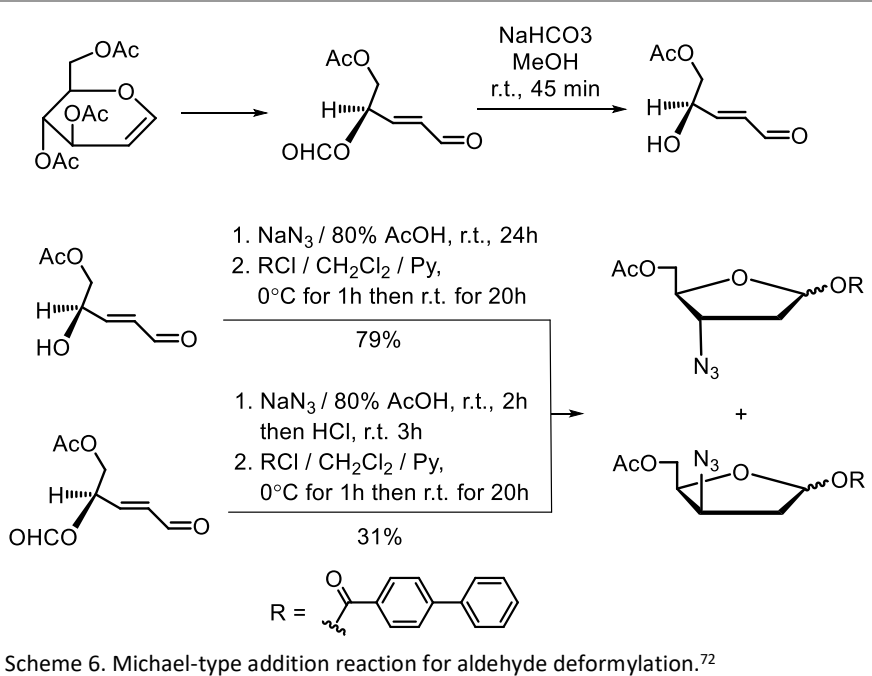

Scheme 6. Michael-type addition reaction for aldehyde deformylation. ${ }^{72}$ 


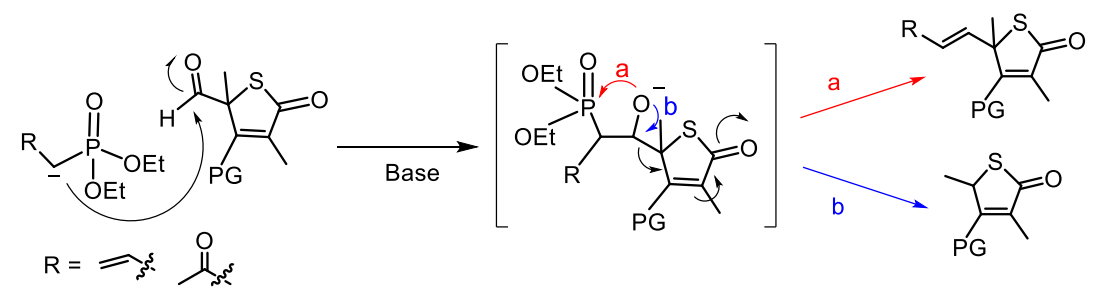

$P G=M O M O$, pyrrolidino

Scheme 7. Proposed competitive mechanisms for aldehyde deformylation and Horner-Wadsworth-Emmons olefination reactions. MOM $=$ methoxymethyl.

Also, thiolactomycin is a natural product that shows a broad spectrum of antibiotic activities. ${ }^{86-89}$ Thus, noteworthy efforts have been made for the synthesis of thiolactomycin and its derivatives. ${ }^{90-98}$

For example, vinyl and diene derivatives of thiolactomycin have been synthesized from stabilized phosphonates and 5-formyl3,5-dimethylthiotetronic acid protected by hydroxy protecting groups such as methoxymethyl (MOM) and pyrrolidino at the $\mathrm{C}_{4}$ position via Horner-Wadsworth-Emmons olefination, and products were obtained in a competitive olefination and deformylation processes (Scheme 7). ${ }^{99}$ It was observed that deformylation is the major competing reaction due to the proaromatic nature of these aldehydes.

Indole is an important heterocycle ${ }^{100-102}$ and has been widely investigated due to its structural and functional analogies to a Trp amino acid residue and consequently its ability to act as a potential therapeutic agent. ${ }^{103,104}$ Synthetic chemists have explored many different methods and procedures for the synthesis of indole-based heterocyclic compounds. Derivatives of indole-3-carboxaldehyde have been reacted through deformylation using various reagents such as diethylene glycol, ethylene glycol or glycerine, ${ }^{105}$ molecular iodine, ${ }^{106}$ and $\mathrm{N}, \mathrm{N}^{\prime}$ dimethlylethylenediamine in water. ${ }^{107}$ In heterogeneous catalysis the deformylation of indole-3-carboxaldehyde, the reaction proceeds via a quinozolinone intermediate using an Amberlyst- 15 catalytic surface at $80^{\circ} \mathrm{C}$ (Scheme 8). ${ }^{108}$

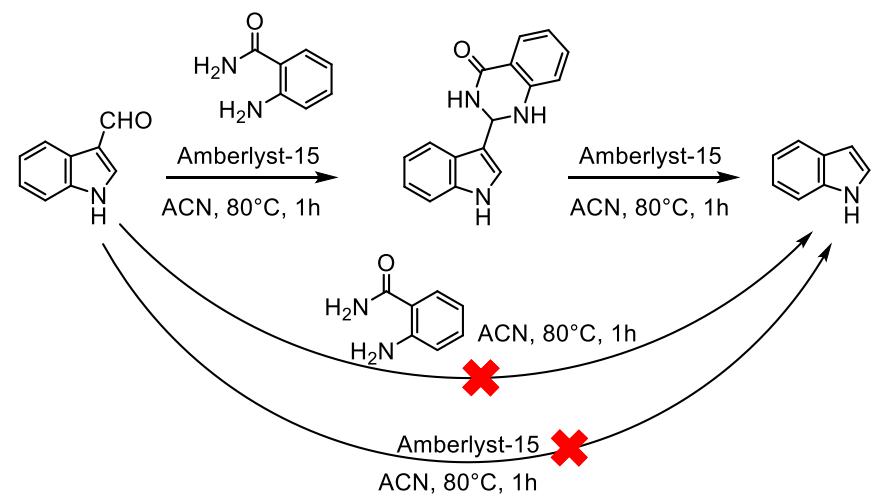

Scheme 8. Deformylation of indole derivatives. $\mathrm{ACN}=$ acetonitrile.
More recently, Su and co-workers reported a convenient method for the synthesis of quinoline derivatives with excellent yields in a short reaction time. Thus, the $\mathrm{N}$-deformylation of their model substrate 4-chloro-2-phenyl- $\mathrm{N}$-formyl-1,2dihydroquinoline was carried out in a solvent-free medium with concomitant aromatization under high-speed ball milling (HSBM) conditions, which helps to provide a recyclable reaction system (Scheme 9). ${ }^{109}$ The reaction needed solid base $\mathrm{NaOH}$ and $\mathrm{NaCl}$ and was run with the addition of a longer chain polyethylene glycol (PEG 2000). Acid catalysed cyclization has been observed in indolizines containing both formyl and alkyne groups and it was found that the reaction proceeds via an unprecedented intramolecular hydroarylation to give rise to benzo[e]pyrido[1,2-a]indole as the deformylative product with an aryl substituent at the $\mathrm{C}_{6}$ position, and a product with acyl substituent at $C_{5}$ formed through intramolecular alkynecarbonyl metathesis. ${ }^{110}$

$$
\text { Scheme 9. }{ }_{\mathrm{N} \text {-deformylation reactions of }}^{\text {4-chloro-2-phenyl- } \mathrm{N} \text {-formyl-1,2- }}
$$
dihydroquinoline.

Coupling reactions are one of the most commonly used methods in organic synthesis, which often take place in the presence of a transition metal ion. ${ }^{111-122}$ However, in recent years, it has been found that coupling reactions can be carried out without the involvement of metal catalysts for the removal of a formyl group. Such an example is shown in Scheme 10, which highlights the metal-free coupling reaction between the phenyliodonium ylide of lawsone with aromatic aldehydes. The reaction is activated by $\mathrm{BF}_{3}$ in diethyl ether and affords the corresponding aryl-hydroxyquinones in high yields. ${ }^{123}$

Chi and co-workers have developed a metal-free approach for the synthesis of various chiral ketones such as $\alpha$-amino ketones, $\alpha, \alpha^{\prime}$-diamino ketones, and $\alpha$-substituted $\beta$-nitro ketones using molecular oxygen as the sole oxidant for the $\mathrm{C}-\mathrm{C}$ bond cleavage of chiral aldehydes. ${ }^{124}$ The products were obtained with high optical purities from the readily available substrates. Apart from 
these examples, a 2,2,6,6-tetramethyl(piperidin-1-yl)oxyl (TEMPO)-mediated oxidative deformylation has been studied in aldehydes to give rise to alkoxyamines. ${ }^{125}$ This is a one-pot reaction process combined with initial oxidation of the corresponding alcohols to aldehydes. Recently, alkyl halides were synthesized by visible light-mediated deformylative halogenation of aldehydes using inexpensive and atomeconomical halogen sources $(\mathrm{NaBr}, \mathrm{Nal}$, or $\mathrm{HCl}) .{ }^{126}$ Under oxidative conditions, 1,4-dihydropyridine (DHP) was derived from an aldehyde, and generated a $\mathrm{C}\left(\mathrm{sp}^{3}\right)$-radical that coupled with a halogen radical to afford an alkyl halide.<smiles>O=C1C([O-])=C([I+](F)(F)c2ccccc2)C(=O)c2ccccc21</smiles><smiles>COc1ccc(C=O)cc1OCC(=O)OCc1ccccc1</smiles><smiles>COc1ccc(C2=C(O)C(=O)c3ccccc3C2=O)cc1OC</smiles>

Reaction conditions Yield

$\mathrm{CH}_{2} \mathrm{Cl}_{2}, \mathrm{rt}, 24 \mathrm{~h}$

$\mathrm{CH}_{2} \mathrm{Cl}_{2}$, reflux, $7 \mathrm{~h}$

$\mathrm{CHCl}_{3}$, reflux, $1.5 \mathrm{~h}$

$40 \%$

$57 \%$

$92 \%$

Scheme 10. Deformylation triggered $\mathrm{C}-\mathrm{C}$ coupling reaction of ylides with aromatic aldehydes.

There are limited reports on metal catalysed aldehyde deformylation reactions involving precious metals. Mostly they invoke a key aldehyde deformylation step that has been extended further for coupling reactions. For instance, Li and coworkers have developed a novel synthetic method of biaryl synthesis, by coupling of aryl $\mathrm{C}-\mathrm{H}$ bonds and aldehydes in the presence of a $\mathrm{Rh}(\mathrm{I})$-catalyst. ${ }^{127}$ Oxidative addition of the aldehyde to the $\mathrm{Rh}(\mathrm{I})$ catalyst generates the $\mathrm{Rh}(\mathrm{III})$ species. Subsequent $\mathrm{CO}$ extrusion and a reaction with arylpyridine through $\mathrm{C}-\mathrm{H}$ activation followed by reductive elimination produces the final biaryl coupling product (Scheme 11).
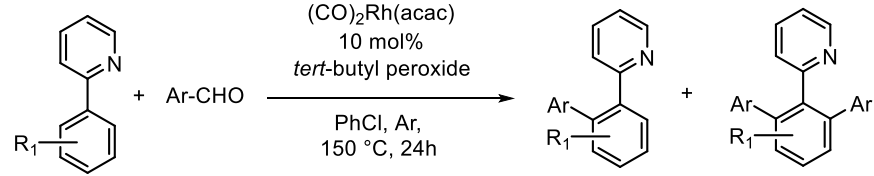

Scheme 11. Oxidative Decarbonylative Arylation of 2-Arylpyridines.

Another such example of aldehyde deformylation reaction used in organic coupling was reported by Rao et al. ${ }^{128}$ Here also, oxidative addition of the rhodium catalyst to salicyaldehyde initiates the catalytic cycle for the coupling reaction and generates a rhodacycle. A migratory $\mathrm{CO}$ deinsertion produces the aryl rhodium hydride species which undergoes carbometallation with an acrylate giving the alkyl rhodium. Finally, $\beta$-hydride elimination from the conjugate produces ohydroxycinnamate and liberates dihydrorhodium which thereby loses $\mathrm{H}_{2}$ (or reacts with acrylate) to regenerate the original catalyst (see Scheme 12).

Thus, based on a literature survey and a comprehension of the hereby discussed examples, a judicious generalization would be that the precious metal ( $4 \mathrm{~d}$ and $5 \mathrm{~d}$ ) catalysed aldehyde deformylation reactions proceed via oxidative addition - where the active site is usually a comparatively low-valent metal. On the contrary, high-valent $3 \mathrm{~d}$-transition metal intermediates (of the likes of metal-peroxo, -hydroperoxo or -superoxo) have been invoked for aldehyde deformylations through either a nucleophilic or an electrophilic pathway.

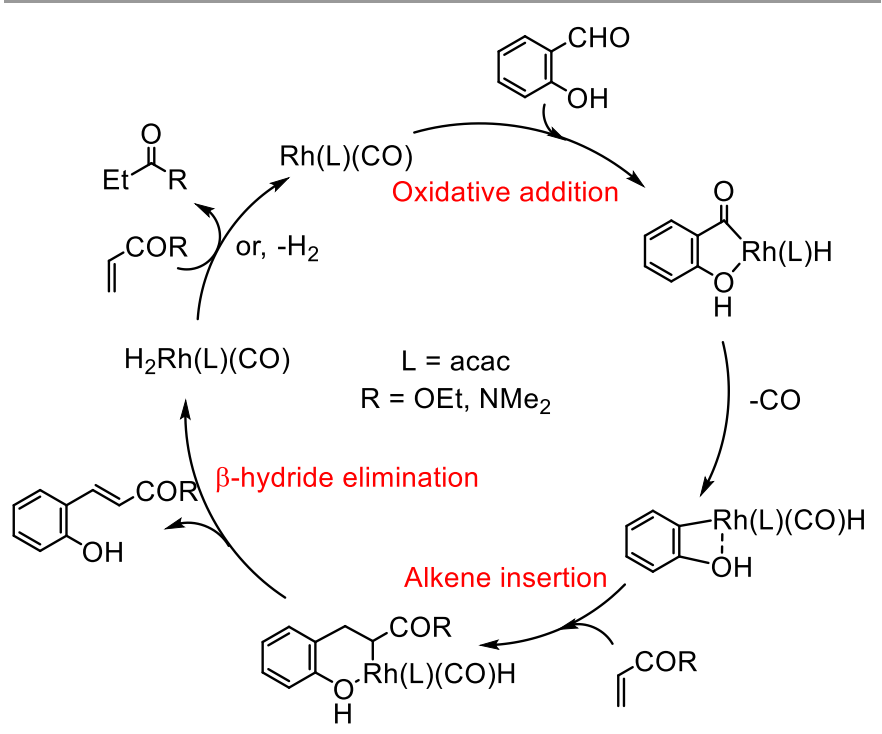

Scheme 12. Proposed mechanism of rhodium catalysed coupling reaction of salicyaldehyde involving aldehyde deformylation.

\section{Aldehyde deformylation by biomimetic non- heme complexes}

Activation of molecular oxygen by metalloenzymes leads to the formation of various high-valent metal-intermediates, including iron(IV)-oxo, iron(III)-peroxo or iron(III)-superoxo. One of the earliest of those characterized spectroscopically was the iron(IV)-oxo species of cytochrome $c$ peroxidase (Compound I) by Hoffman and co-workers. ${ }^{129,130}$ Interestingly, this species was shown to contain radical character on the iron(IV)-oxo group coupled to a radical on a nearby Trp residue. In P450 CAM, the iron(IV)-oxo heme cation radical (Compound I) was characterised by Rittle and Green using a combination of UV-Vis spectroscopy and electron paramagnetic resonance and Mössbauer spectroscopic studies. ${ }^{49}$ Compound I was shown to perform various oxidative reactions including aliphatic and aromatic hydroxylation, epoxidation, but also $\mathrm{N}$-dealkylation and O-demethylation reactions. ${ }^{26-28,131,132}$ Computational modelling using density functional theory or quantum mechanics/molecular mechanics methods established the details of the reaction mechanisms for various oxygen atom transfer processes by the P450s. ${ }^{37-39}$ In non-heme iron enzymes, the iron(IV)-oxo species was trapped and characterized for a variety of hydroxylases and halogenases. ${ }^{133-136}$ Electronically, the non-heme iron(IV)-oxo species differs from $\mathrm{P} 450$ Compound I as it misses one reduction equivalent, i.e. the heme radical, and hence differences in 
reactivity patterns are often seen. Thus comparative computational studies on P450 and non-heme iron(IV)-oxo cluster models showed enhanced reactivity of the non-heme system due to the formation of a highly stable exchangeenhanced high-spin radical intermediate. ${ }^{137-139}$

Another high-valent intermediate that has been characterized in mononuclear iron enzymes (naphthalene 1,2-dioxygenase, benzoate 1,2-dioxygenase, cytochrome P450 and methane monooxygenase) is the non-heme iron(III)-peroxo intermediate. ${ }^{140}$ The dioxygen adduct can be described as either iron(III)-peroxo or iron(II)-superoxo depending on the chargetransfer from metal to peroxo group. Moreover, it can appear in either the end-on $\left(\eta_{1}\right)$ or side-on $\left(\eta_{2}\right)$ conformation. These end-on and side-on species are known to react differently with substrates. ${ }^{141-144}$ In particular, the side-on metal peroxo complexes are known to exhibit various nucleophilic reactions including aldehyde deformylation. To gain insight into the ligand and second-coordination sphere effects of metal centres in enzymes, in bioinorganic chemistry many synthetic models have been created that mimic the structural and functional features of enzymes. ${ }^{145-149}$ These biomimetic models are covered in the following sections including recent results on aldehyde deformylation reaction mechanisms of synthetic biomimetic coordination complexes.

\subsection{Aldehyde deformylation by $\mathrm{V}^{5+}$ complexes}

Metal mediated decarbonylation of aldehydes and/or halogenation reactions are not rare. However, decarbonylation and subsequent halogenation of aldehydes was accomplished by Maiti and co-workers only recently through the use of a synthetic divanadium oxoperoxo complex, $\mathrm{K}_{3}\left(\mathrm{~V}^{5+}\right)_{2}\left(\mathrm{O}_{2}{ }^{2-}\right)_{4}\left(\mathrm{O}^{2-}\right)_{2}(\mu-\mathrm{OH})\left[\mathrm{K}_{3} \mathrm{~V}_{2} \mathrm{O}_{12} \mathrm{H}_{3}\right] .{ }^{150}$

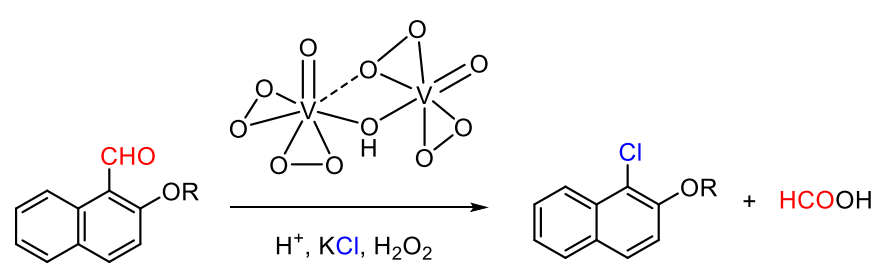

Scheme 13. Decarbonylative halogenation by a divanadium oxoperoxo complex

Substrates like 2-hydroxy-1-naphthaldehyde and 2-methoxy-1naphthaldehyde were catalysed by the divanadium oxoperoxo intermediate in the presence of $\mathrm{H}_{2} \mathrm{O}_{2}$ and $\mathrm{KCl}$ (or $\mathrm{KBr}$ ) leading to the formation of the corresponding decarbonylative halogenated products and formic acid, as shown in Scheme 13. The reaction mechanism triggered further experimental studies as well as supporting density functional theory calculations. ${ }^{150}$

As exhibited in Scheme 14, the aldehyde substrate moiety is proposed to bind to the vanadium-oxoperoxo complex in a bidentate fashion. In the presence of a halide ion and $\mathrm{H}_{2} \mathrm{O}_{2}$, the peroxo attacks the carbonyl center generating formic acid and the halogenated product along with regeneration of the active species. Notably, the +5-oxidation state of vanadium was consistent throughout the catalytic cycle. The latter was also seen by recent studies on the catalytic cycle of the vanadium- haloperoxidase enzyme, where the vanadium remained in the $\mathrm{V}^{\mathrm{V}}$ oxidation state throughout. ${ }^{152}$ In particular, it functioned as a reaction scaffold by binding $\mathrm{H}_{2} \mathrm{O}_{2}$ to form a vanadium(V)hydroperoxo complex that in a reaction with halide formed hypohalide anions.

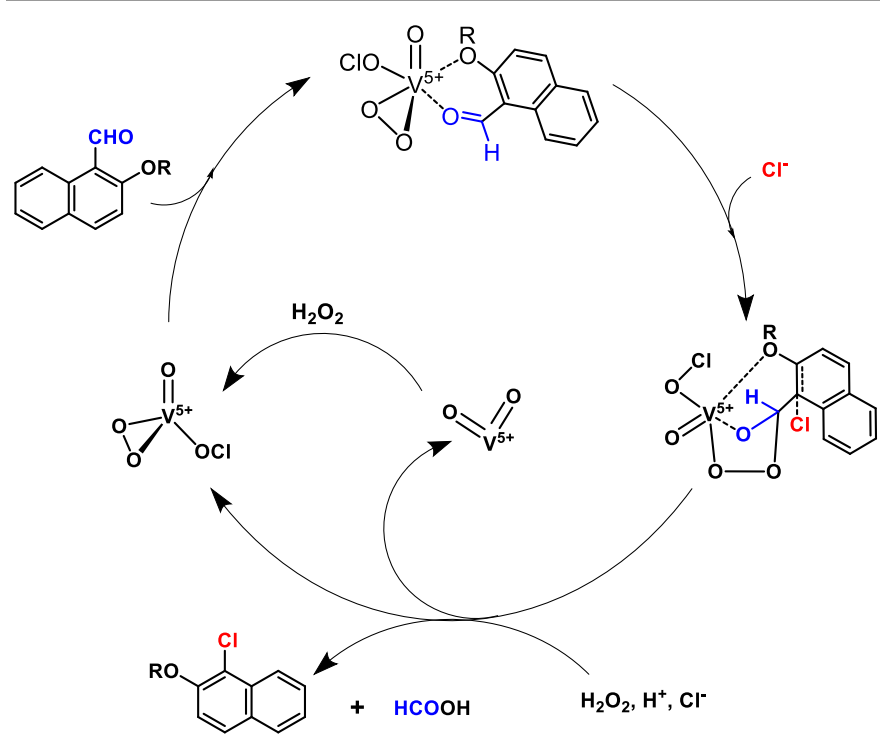

Scheme 14. Proposed mechanism of vanadium catalysed decarbonylative halogenation.

\subsection{Aldehyde deformylation by $\mathrm{Mn}^{3+}$-complexes}

Manganese functions as an essential co-factor in various metalloenzymes in biology. Manganese(III)-peroxo complexes have been postulated as a reactive intermediate in the catalytic cycles of several manganese-containing enzymes such as superoxide dismutase, catalase, manganese dioxygenase, oxalate oxidase, as well as in the cubane-type structure of the oxygen-evolving Photosystem II complex. ${ }^{153-160}$ Many biomimetic models of these enzymes have been created over the past few decades. In 2007, Nam and co-workers reported the synthesis and characterization of a manganese(III)-peroxo complex embedded in a tetradentate TMC ligand, [Mn"'I-(13$\left.\mathrm{TMC})\left(\mathrm{O}_{2}\right)\right]^{+}$with $13-\mathrm{TMC}=1,4,7,10$-tetramethyl-1,4,7,10tetraazacyclotridecane. ${ }^{161}$

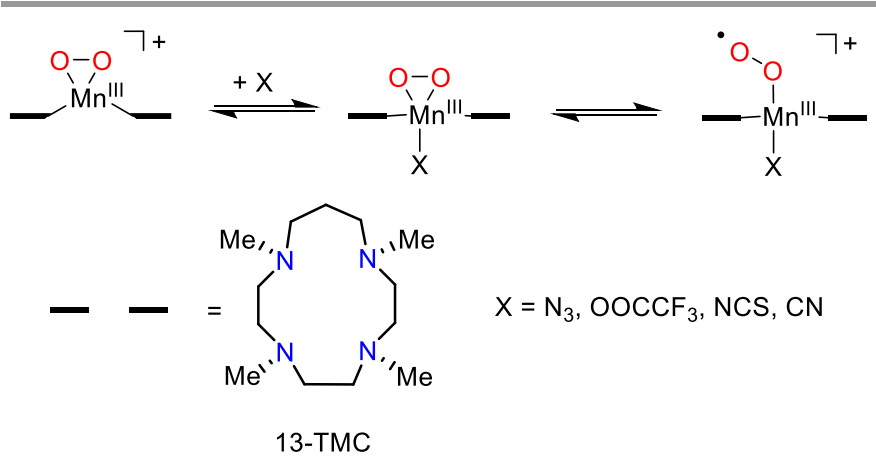

Scheme 15. Conversion of manganese(III)-peroxo to manganese(III)-superoxo by the binding of axial ligands. 


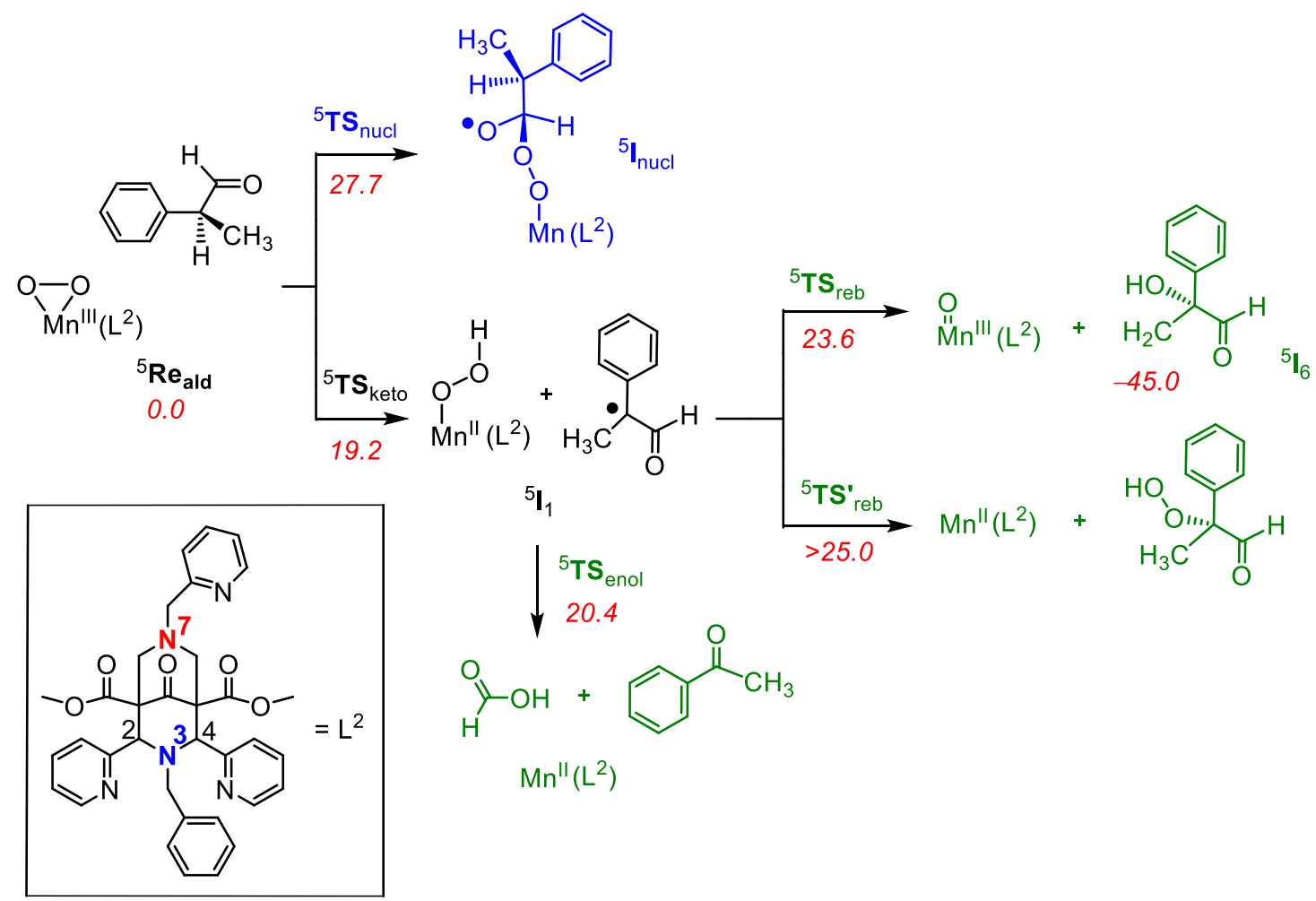

Fig. 2. DFT calculated reaction mechanism of aldehyde deformylation of PPA by a manganese(III)-peroxo complex via nucleophilic and electrophilic mechanisms. Free energies are in $\mathrm{kcal} \mathrm{mol}^{-1}$ and transition state geometries give bond lengths in angstroms and the imaginary frequency of the transition state in $\mathrm{cm}^{-1}$. Data from Ref 168 .

They proposed that the complex undergoes aldehyde deformylation by a nucleophilic reaction where cyclohexanecarboxaldehyde (CCA) is deformylated to form cyclohexene as the major product. Furthermore, the nucleophilicity of the manganese(III)-peroxo complex substantially increased by the addition of anionic axial ligands trans to the peroxo group. ${ }^{162}$ The authors reasoned that the complex could see the conversion of the side-on peroxo unit to an end-on peroxo species through the binding of an axial ligand to the metal centre. In particular, the axial ligand was seen to pull the metal into the plane through the four nitrogen atoms of the 13-TMC ligand. With an axial ligand bound, the complex was found in a favourable end-on conformation, while the complex without axial ligand preferred the side-on orientation. The end-on structure was speculated to be more nucleophilic in a reaction with aldehydes. Further studies on mononuclear manganese(III)-peroxo and dinuclear ( $\mu$-oxo)-bridged dimanganese(III) complexes with common $\mathrm{N}$-methylated macrocyclic ligands were performed. ${ }^{163}$ These studies confirmed a nucleophilic reaction mechanism for aldehyde deformylation reactions by manganese(III)-peroxo complexes. Subsequently, Jackson et al have prepared and characterized a series of manganese(III)-peroxo complexes with tetradentate aminopyridyl ligands. ${ }^{164-166}$ In particular, the effect of steric hindrance and electronic properties on the nucleophilic reactivity in aldehyde deformylation reactions by manganese(III)-peroxo complexes was investigated. The reactivity patterns of manganese(III)-peroxo complexes were studied with cyclohexanecarboxaldehyde (CCA) and 2phenylpropionaldehyde (PPA). Product distributions were only obtained upon the addition of acid to the system, which led the authors to hypothesize that the conversion of manganese(III)peroxo to a hydroperoxo was needed prior to the reactivity with substrates. In addition, it was found that the reactions were sensitive to steric hindrance of the ligand scaffold that blocked substrate approach and positioning and afforded slower rates of deformylation reactions.

Recently, our groups showed that manganese(III)-peroxo complexes with a pentadentate bispidine ligand system react with aldehydes through a deformylation reaction that is initiated with a rate-determining hydrogen atom abstraction reaction. ${ }^{167-170}$ The project was initiated by a computational study that implicated a rate-determining hydrogen atom abstraction reaction for the process of manganese(III)-peroxo with PPA. 


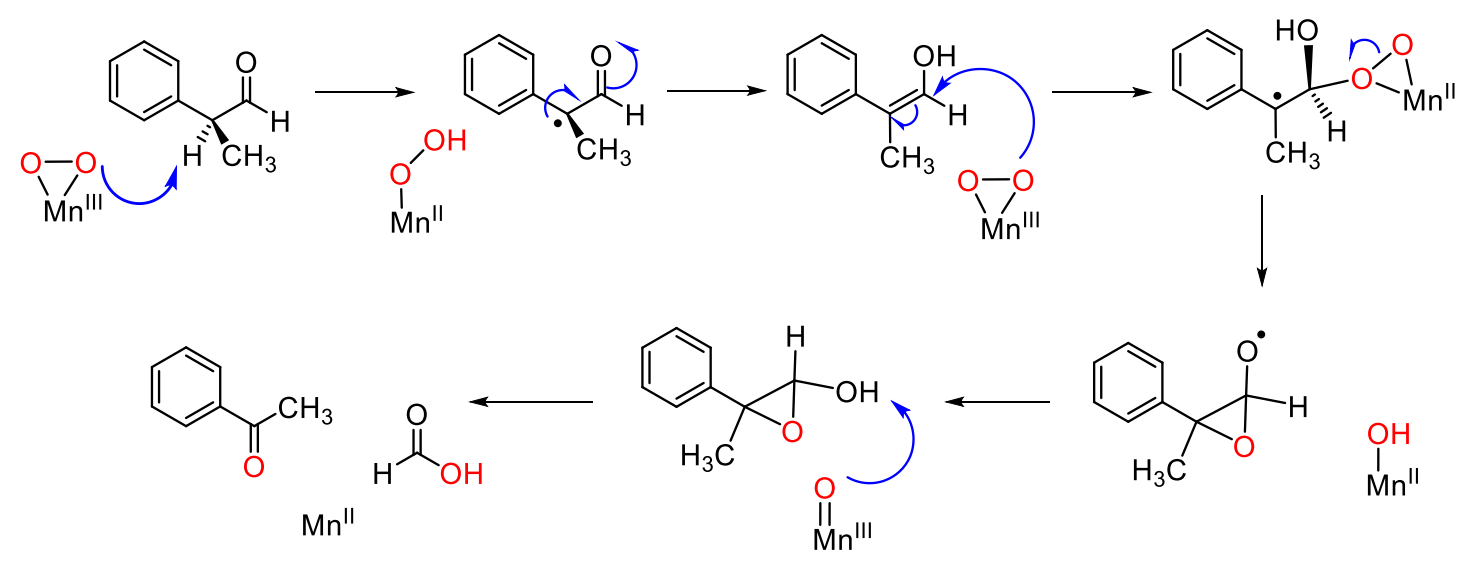

Scheme 16. Reaction mechanism for the electrophilic $\mathrm{C}^{\alpha}-\mathrm{H}$ atom abstraction by manganese(III)-peroxo from PPA.

The complex utilized the pentadentate $\mathrm{N}$-based ligand system $\mathrm{L}^{2}$ or dimethyl-2,4-di(2-pyridyl)-3-benzyl-7-(pyridin-2-ylmethyl)3,7-diazabicyclo[3.3.1] nonan-9-one-1,5-dicarboxylate. Starting from a side-on manganese(III)-peroxo complex the lowest energy pathway was found to be a hydrogen atom abstraction from the benzyl position of PPA to form an end-on manganese(II)-hydroperoxo species and a substrate radical with a free energy of activation of $\Delta \mathrm{G}^{\ddagger}=19.2 \mathrm{kcal} \mathrm{mol}^{-1}$ (Fig. 2). This intermediate was found to undergo keto-enol tautomerization through a ping-pong mechanism, where the proton is reshuttled between the manganese(II)-hydroperoxo species and substrate to eventually form the enol-form of the substrate. From the enol-form in a nucleophilic reaction mechanism via a barrier of $\Delta \mathrm{G}^{\ddagger}=20.4 \mathrm{kcal} \mathrm{mol}^{-1}$ the reaction gives methyl phenyl ketone and formic acid. The computational work reproduced the experimentally determined products from the reaction. Alternative pathways, such as direct $\mathrm{OH}$ rebound via ${ }^{5} \mathbf{T S}_{\text {reb }}$ by the manganese(II)-hydroperoxo to the keto radical had a barrier of $\Delta \mathrm{G}=23.6 \mathrm{kcal} \mathrm{mol}^{-1}$ and hence is unlikely. Similarly, hydroperoxo rebound to the keto radical via ${ }^{5} \mathbf{T S}_{\text {reb }}$ to form 2phenyl-2-hydroperoxy propionaldehyde had an even higher barrier of well over $25.0 \mathrm{kcal} \mathrm{mol}^{-1}$. Nevertheless, all of these barriers were well lower than the direct nucleophilic attack of the side-on manganese(III)-peroxo on the substrate carbony group, which had a free energy of activation of $\Delta G^{\ddagger}=27.7 \mathrm{kcal}$ $\mathrm{mol}^{-1}$. It was concluded that the reaction; therefore, is electrophilic in nature and should take place with a ratedetermining hydrogen atom abstraction reaction rather than a nucleophilic attack. ${ }^{168}$

10 | Org. Biomol. Chem., 2020, 00, 1-3

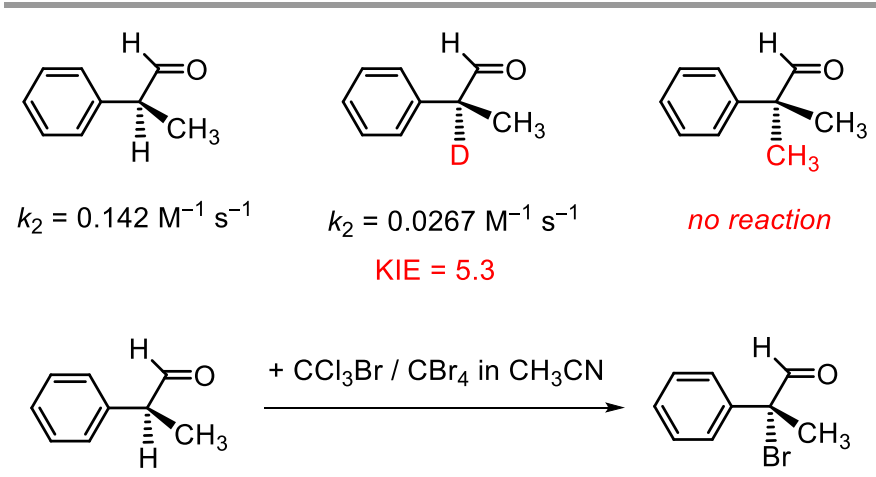

Fig. 3. Reaction of $\left[\mathrm{Mn}\left(\mathrm{O}_{2}\right)\left(\mathrm{L}^{2}\right)\right]^{+}$with PPA and analogues. Product distributions and experimentally determined second-order rate constants in acetonitrile at $15^{\circ} \mathrm{C}$.

To confirm the proposed mechanism from computation, a series of experimental studies were performed that measured rate-constants spectroscopically and determined product distributions of the reaction of $\left[\mathrm{Mn}\left(\mathrm{O}_{2}\right)\left(\mathrm{L}^{2}\right)\right]^{+}$with substrate and substrate-analogues. ${ }^{166-168}$ Thus, spectroscopic studies determined second-order rate constants and reaction products for the reaction of manganese(III)-peroxo $\left(L^{2}\right)$ complexes with PPA and PPA analogues to gain insight into the reaction mechanism, Fig. 3. The reaction of $\left[\mathrm{Mn}\left(\mathrm{O}_{2}\right)\left(\mathrm{L}^{2}\right)\right]^{+}$with PPA gave a second-order rate constant of $k_{2}=0.142 \mathrm{M}^{-1} \mathrm{~s}^{-1}$ at $15^{\circ} \mathrm{C}$ in acetonitrile. By contrast, upon deuteration of the $\mathrm{C}^{\alpha}-\mathrm{H}$ position of substrate, i.e. $\alpha-\left[D_{1}\right]-P P A$, a much lower second-order rate constant of $k_{2}=0.0267 \mathrm{M}^{-1} \mathrm{~s}^{-1}$ was determined under the same reaction conditions. Based on these values a kinetic isotope effect of $\mathrm{KIE}=k_{\mathrm{H}} / k_{\mathrm{D}}=5.3$ was determined. A KIE of this magnitude generally implicates a rate-determining hydrogen atom abstraction reaction. ${ }^{171}$ 

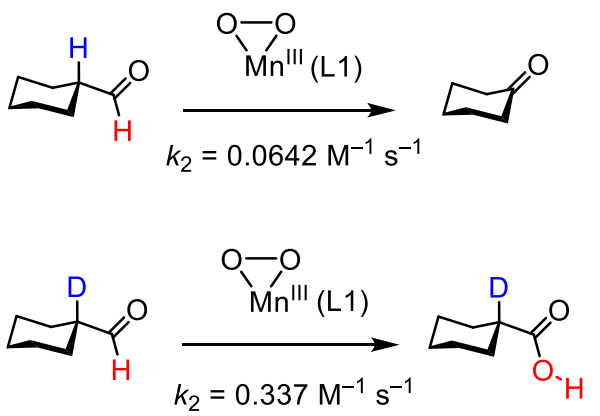
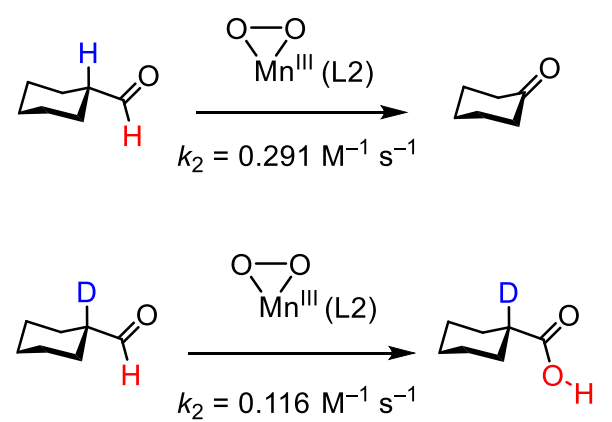

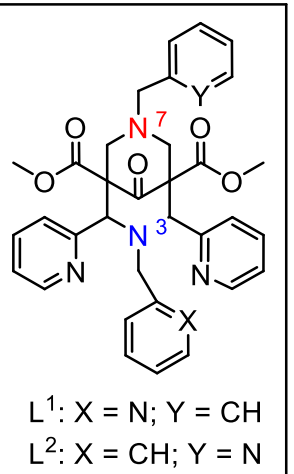

$L^{1}: X=N ; Y=C H$
$L^{2}: X=C H ; Y=N$

Scheme 17. Product distributions from the reaction of $\left[\mathrm{Mn}\left(\mathrm{O}_{2}\right)\left(\mathrm{L}^{1}\right)\right]^{+}$and $\left[\mathrm{Mn}\left(\mathrm{O}_{2}\right)\left(\mathrm{L}^{2}\right)\right]^{+}$with $\mathrm{CCA}$ and deuterated CCA. Experimentally measured rate constants determined at $15^{\circ} \mathrm{C}$ in acetonitrile.

To find further evidence that the reaction proceeds through hydrogen atom abstraction of the $\mathrm{C}^{\alpha}-\mathrm{H}$ position, a PPA analogue with two methyl groups on the $\mathrm{C}^{\alpha}$-position, i.e. 2phenyl-2-methyl propionaldehyde, as a substrate was used. However, no products were detected for this reaction, which is further evidence that no nucleophilic reaction mechanism takes place with PPA as a substrate.

Finally, a radical trapping experiment was performed between $\left.\left[\mathrm{Mn}\left(\mathrm{O}_{2}\right) \mathrm{L}^{2}\right)\right]^{+}$and PPA with the addition of $\mathrm{CCl}_{3} \mathrm{Br}$ and $\mathrm{CBr}_{4}$ in acetonitrile. This radical trapping experiment indeed produced 2-phenyl-2-bromo-propionaldehyde as products and confirms the operation of a radical mechanism. These biomimetic manganese(III)-peroxo complexes; therefore, operate under an unusual electrophilic-type mechanism rather than the commonly accepted nucleophilic pathways, Scheme 16 Interestingly, the $\left[\mathrm{Mn}\left(\mathrm{O}_{2}\right)\left(\mathrm{L}^{2}\right)\right]^{+}$complex does not react with cyclohexadiene as a substrate, which appears to implicate that the complex can only do a single hydrogen atom abstraction step and the manganese(II)-hydroperoxo species is a sluggish oxidant. These unexpected observations of a possible electrophilic reaction mechanism triggered us to investigate the reactivity patterns of bispidine-ligated manganese(III)-peroxo complexes in more detail. In particular, a study with cyclohexane carboxaldehyde (CCA) was performed. ${ }^{169}$ Our mechanistic studies indeed unfolded further possibilities in terms of regioselectivity in substrate approach towards the deformylating catalyst. In particular, in the reaction of the same class of mononuclear non-heme manganese(III)-peroxo complexes with CCA, the isotopic substitution of the $\alpha$ hydrogen in cyclohexanecarboxaldehyde (CCA) switches the reactivity regioselectively from the aliphatic $\mathrm{C}^{\alpha}-\mathrm{H}$ hydrogen atom abstraction to aldehyde hydrogen atom abstraction. ${ }^{169}$ Upon addition of CCA to the manganese(III)-peroxo complex, the intermediate decayed to afford cyclohexanone as a product. As discussed earlier, this reaction also proceeded via a ratedetermining hydrogen atom abstraction from the $\mathrm{C}^{\alpha}-\mathrm{H}$ position of the aldehyde. Surprisingly, upon addition of $\alpha-\left[D_{1}\right]-C C A$ to the $\left[\mathrm{Mn}^{\prime \prime \prime}\left(\mathrm{O}_{2}\right)\left(\mathrm{L}^{1}\right)\right]^{+}$complex, the rate of the reaction enhanced by 50 folds as compared to that of CCA with a KIE of 0.02. Also, the product analysis revealed the formation of cyclohexane carboxylic acid instead of the expected cyclohexanone. These studies clearly imply that a regioselectivity switch has occurred upon deuteration of the substrate and instead of the $\mathrm{C}^{\alpha}-\mathrm{H}$ hydrogen atom abstraction the aldehyde hydrogen atom is abstracted.

To complement the experimental work, a series of density functional theory calculations were performed. Two reaction pathways were investigated, namely for hydrogen atom abstraction for the $\mathrm{C}^{\alpha}-\mathrm{H}$ and aldehyde $\mathrm{C}-\mathrm{H}$ bonds of CCA. The DFT calculations located the two transition states to within 1 kcal $\mathrm{mol}^{-1}$ of energy. However, the substitution of the transferring hydrogen atom by deuterium results in an increase of the barrier height and hence triggers a regioselectivity switch from $\mathrm{C}^{\alpha}-\mathrm{H}$ activation to aldehyde $\mathrm{C}-\mathrm{H}$ activation in agreement with experimental observation.

These results indicate that the non-deuterated substrate gives cyclohexanone as products, while $C^{\alpha}-D$ substituted CCA gives cyclohexane carboxylic acid as products. A similar regioselectivity switch through the substitution of hydrogen atoms in the substrate by deuterium was seen by Nam et al for ethylbenzene activation by an iron(IV)-oxo porphyrin complex and confirmed with DFT calculations. ${ }^{172,173}$

\subsection{Aldehyde deformylation by biomimetic $\mathrm{Fe}^{3+}$ complexes}

Iron is one of the main constituents in many metalloenzymes and metalloproteins that perform an aldehyde deformylation reaction. ${ }^{8-25}$ Nam and co-workers synthesized and characterized a mononuclear nonheme iron(III)-peroxo complex bearing a macrocyclic tetradentate N4 ligand system, $\left[(\mathrm{TMC}) \mathrm{Fe}^{\prime \prime \prime}\left(\mathrm{O}_{2}\right)\right]^{+}$with $\mathrm{TMC}=1,4,8,11$-tetramethyl-1,4,8,11tetraazacyclotetradecane. ${ }^{174}$ This complex was found to be capable of performing aldehyde deformylation reactions with 2 - 
PPA as a substrate. The product analysis revealed acetophenone as the predominant product along with the formation of a formate. Isotope labelling studies with $\left[(T M C) \mathrm{Fe}^{\prime \prime \prime}\left({ }^{18} \mathrm{O}_{2}\right)\right]^{+}$revealed that the oxygen in the acetophenone product is derived from the peroxo group and does not exchange with water from the solution (Scheme 18).

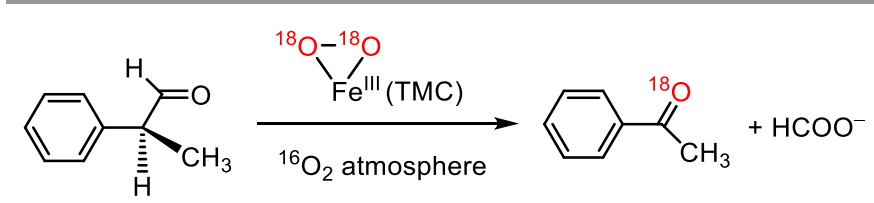

Scheme 18. Aldehyde deformylation of PPA by a biomimetic iron-peroxo complex.

Subsequently, research from the same group was focused on comparative reactivity studies of the iron-intermediates, i.e. iron-hydroperoxo, iron-peroxo and iron-oxo, and concluded that the iron(III)-peroxo complexes are capable of conducting aldehyde deformylation via a nucleophilic pathway. ${ }^{175}$ Thus, reactivity studies of iron(III)-peroxo with thioanisole or cyclohexene gave no evidence of reaction products, whereas with 2-PPA as a substrate acetophenone was obtained as the major reaction product. These reactivity studies were interpreted as originating from a nucleophilic reaction mechanism although no mechanistic evidence was provided. Furthermore, the studies with the TMC ligand system revealed that the iron(III)-hydroperoxo species as compared to the iron(III)-peroxo and iron(IV)-oxo is the most reactive intermediate towards the aldehyde deformylation reaction. ${ }^{176}$ Nivière and co-workers carried out aldehyde deformylation reactions by a mononuclear non-heme high-spin iron(III)hydroperoxo complex. ${ }^{177}$ This complex was generated in superoxide reductase and showed nucleophilic character and reacted through oxidative aldehyde deformylation with substrates. A biomimetic model of the cyanobacterial aldehyde deformylation oxygenase (CADO) was synthesized and characterized by Shokri and Que as an iron (III)-peroxo complex, $\left[\mathrm{Fe}^{\prime \prime \prime}\left(\mathrm{n}^{2}-\mathrm{O}_{2}\right)(\mathrm{TMC})\right]^{+}$, that converts aldehydes such as PPA and undecanal into their corresponding alkanes in tetrahydrofuran solvent, in the presence of a suitable hydrogen atom donor. ${ }^{178}$ The proposed mechanism for this transformation involves the conversion of the side-on iron(III)-peroxo complex into an endon peroxo, which then reacts with aldehydes. Subsequently, a peroxyhemiacetal adduct is formed that undergoes homolytic O-O bond cleavage to afford an alkyl radical, a formate, and iron(IV)-oxo species. Finally, interception of this alkyl radical with a suitable hydrogen atom donor gives alkane as the product. The reactivity patterns of these non-heme iron model systems; however, appear to be highly dependent on external (environmental) factors. Thus, recently it was pointed out that the reaction selectivity of aldehyde deformylation may switch depending on the temperature. In particular, Fukuzumi and coworkers found a bifurcation pathway in aldehyde deformylation by a non-heme iron(III)-hydroperoxo complex, i.e. $\left[\mathrm{Fe}^{\prime \prime \prime}(\mathrm{OOH})(\mathrm{TMC})\right]^{2+}$, whereby temperature was the controlling factor. ${ }^{179}$ At temperatures above $248 \mathrm{~K}$, the deformylation of 2PPA and its derivatives was found to proceed via a nucleophilic addition reaction. However, the mechanism switches to hydrogen atom transfer as the temperature is lowered. A bifurcation pathway was suggested which is due to the tunnelling effect in the hydrogen atom transfer reaction.

\subsection{Aldehyde deformylation by biomimetic $\mathrm{Co}^{3+}$ complexes}

$\mathrm{Nam}$ and co-workers reported the characterization of a cobalt(III)-peroxo complex bearing the tetradentate TMC ligand and investigated its reactivity towards aldehyde deformylation reaction with various aldehydes. ${ }^{180}$ The cobalt(III)-peroxo complexes were characterized with X-ray crystallography, UVVis absorption, resonance Raman spectroscopy and electron paramagnetic resonance studies. Upon comparison of its reactivity with the analogous iron(III) and manganese(III)peroxo complexes, the reactivity order with aldehydes was found to be $\left[\mathrm{Mn}^{\prime \prime \prime}\left(\mathrm{O}_{2}\right)(\mathrm{TMC})\right]^{+}>\left[\mathrm{Co}^{\prime \prime \prime}\left(\mathrm{O}_{2}\right)(\mathrm{TMC})\right]^{+}>$ $\left[\mathrm{Fe}^{\mathrm{III}}\left(\mathrm{O}_{2}\right)(\mathrm{TMC})\right]^{+}$. A positive Hammett $\rho$-value of 1.8 was determined for aldehyde deformylation of para-X-Ph-CHO (X= OMe, Me, F, H, Cl) as substrates by the cobalt(III)-peroxo complex; hence a nucleophilic reaction mechanism was proposed.

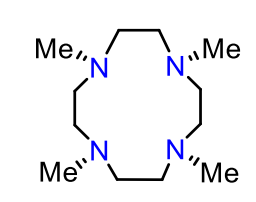

12-TMC

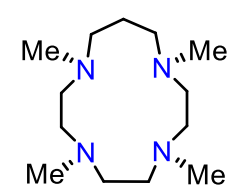

13-TMC

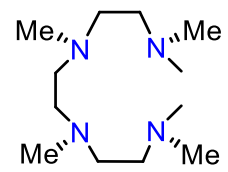

$\mathrm{Me}_{6}$-trien
Scheme 19. Tetradentate 12-TMC, 13-TMC and $\mathrm{Me}_{6}$-trien ligands used as biomimetic models.

Subsequent studies focused on the effect of the ring size of the TMC ring on the reactivity of cobalt(III)-peroxo complexes towards aldehyde deformylation reaction. ${ }^{181}$ In particular, two mononuclear cobalt(III)-peroxo complexes were investigated, namely the tetradentate 12-TMC and 13-TMC ligands, Scheme 19. The larger ring size was found lead to an oxidant that was more reactive towards nucleophilic addition to aldehydes. Especially, the [Co"l' $\left.\left(\mathrm{O}_{2}\right)(13-\mathrm{TMC})\right]^{+}$complex was found to be more reactive with respect to aldehyde deformylation than the corresponding [Co $\left.{ }^{\prime \prime \prime}\left(\mathrm{O}_{2}\right)(12-\mathrm{TMC})\right]^{+}$species. Interestingly, these side-on cobalt(III)-peroxo complexes were also shown to react through $\mathrm{O}_{2}$ transfer to manganese(II) complexes efficiently. In addition, the same group has proposed a cobalt(III)hydroperoxo complex bearing a tetramethylated cyclam ligand (12-TMC), which exhibits amphoteric reactivity in electrophilic oxidation (hydrogen atom and oxygen atom transfer) and nucleophilic oxidation, e.g., aldehyde deformylation reactions. ${ }^{182}$

Goldsmith et al synthesized and characterized a cobalt(III)peroxo complex with the tetradentate BBPC ligand, BBPC = $\mathrm{N}, \mathrm{N}^{\prime}$-dibenzyl-N, $\mathrm{N}^{\prime}$-bis(2-pyridylmethyl)-1,2-cyclohexane diamine. ${ }^{183}$ The reactivity of this peroxo complex in aldehyde deformylation was investigated with CCA as a substrate and it was observed that the reaction follows a nucleophilic reaction pathway that forms cyclohexene as a product. Recently, Cho et al reported a cobalt(III)-bis(tert-butylperoxo) complex, 
[Co'I'(OOtBu $)_{2}$ ] bearing a tetraazamacrocyclic ligand. ${ }^{184}$ The complex is capable of undergoing nucleophilic reaction efficiently.

\subsection{Aldehyde deformylation by biomimetic $\mathrm{Ni}^{2+}$ complexes}

Nickel is one of the most valuable transition metals in promoting numerous organic reactions due to its inherent redox properties. ${ }^{185-187}$ In recent years, nickel-dioxygen adducts of biomimetic non-heme systems have gained a lot of attention owing to their ability to act as oxidizing agents. For example, Akita and co-workers have studied the reactivity of the nickel(II)-alkylperoxo complex, [Ni(OOtBu)(TpiPr)], with a series of para-substituted benzaldehydes produced the corresponding benzoato adducts [ $\left.\mathrm{Ni}^{\prime \prime}\left(\kappa^{2}-\mathrm{OOCC}_{6} \mathrm{H}_{4}-\mathrm{p}-\mathrm{X}\right)(\mathrm{TpiPr})\right](\mathrm{X}=\mathrm{OMe}, \mathrm{Me}$ $\mathrm{H}, \mathrm{Cl}) .{ }^{188}$ By plotting the natural logarithm of the first-order rate constant $\left(k_{\text {obs }}\right)$ versus the $\sigma$-Hammett parameter a linear correlation with a positive slope with $\rho=4.3$ was obtained. It was evidenced that the oxidation of these aldehydes proceeds through a nucleophilic pathway and the substituents present at the para-position have a major role in stabilizing the transition states.

Further studies of Nam and co-workers reported a highresolution crystal structure of the side-on nickel(III)-peroxo complex with a 12-membered macrocyclic ligand, [ $\mathrm{Ni}^{\prime \prime \prime}\left(\mathrm{O}_{2}\right)(12$ TMC)] ${ }^{+} .{ }^{189}$ They have investigated with both 2-PPA and CCA as substrate and produced acetophenone and cyclohexene, respectively, as evidence of a nucleophilic aldehyde deformylation reaction. However, the reactivity patterns of nickel(III)-peroxo adducts are dependent on the ring size of the supporting ligands, ${ }^{189}$ electronic effect, ${ }^{190}$ and steric effect. ${ }^{191}$ Nucleophilic deformylation of aldehydes has also been reported for a monoanionic nickel(II)-superoxo intermediate, $\left[\mathrm{Ni}^{11} \mathrm{O}_{2}(\mathrm{~L})\right]^{-}$ , $\left.\mathrm{L}=\operatorname{MeN}\{\mathrm{C}(=\mathrm{O}) \mathrm{NAr}\}_{2} ; \mathrm{Ar}=2,6-\mathrm{iPr}_{2} \mathrm{C}_{6} \mathrm{H}_{3}\right] .{ }^{192}$ Cho and co-workers have synthesized a nickel(III)-peroxo complex with the $\mathrm{Me}_{6^{-}}$ trien ligand, which is an analogue of the macrocyclic 12-TMC ligand but with an open chain structure, Scheme 15. They have compared the reactivity of nickel(III)-peroxo intermediates of both $\mathrm{Me}_{6}$-trien and 12-TMC ligands and found that open-chain nickel(III)-peroxo complex is more reactive than the macrocyclic analogue towards aldehyde deformylation. ${ }^{193}$

\subsection{Aldehyde deformylation by biomimetic $\mathrm{Cu}^{2+}$ complexes}

Copper is one of the essential elements in living organisms, which plays an important role in biology. ${ }^{194,195}$ McDonald et al proposed the nucleophilic character of a copper(II)-superoxide complex, with [N,N]-bis(2,6-diisopropylphenyl)-2,6- pyridinedicarboxamido] ligand as a mimic of non-heme iron $\alpha$ ketoglutarate and pterin dependent enzymes. ${ }^{196}$ Here, the endon copper(II)-superoxo complex reacts with acyl chloride substrates to form carboxylic acids (Scheme 20a). It was suggested that a nucleophilic mechanism applies, where the terminal oxygen atom of the superoxo group attacks the carbonyl group to form a covalent $\mathrm{C}-\mathrm{O}$ bond. Subsequently, the halide is released and a peracid-bound copper(III) complex is formed. The latter reacts through homolytic cleavage of the $\mathrm{O}-\mathrm{O}$ bond to form phenylacetic acid products. In addition, the copper(II)-superoxo complex was shown to react through aldehyde deformylation by undergoing Bayer-Villager oxidation of electron rich aldehydes (Scheme 20b). ${ }^{196}$

A copper-alkylperoxo complex that shows nucleophilic reactivity in aldehyde deformylation reaction was proposed by Cho et al. ${ }^{197}$ The nucleophilic attack on the carbonyl carbon was confirmed from a positive Hammett value of 3.7 for the reaction of copper-alkylperoxo with para-substituted benzoyl chlorides. These systems reacted to form a peroxyhemiacetal-type intermediate that undergoes homolytic $\mathrm{O}-\mathrm{O}$ bond cleavage to give the deformylated products. In subsequent studies the same group demonstrated the nucleophic reactivity of an endon copper(II)-hydroperoxo complex. ${ }^{198}$ A positive Hammett value of 2.0 for the reaction of copper(II)-hydroperoxo with para-substituted acyl chlorides implicated the nucleophilic character of the copper(II)-hydroperoxo complex. The system was also reactive towards CCA and 2-PPA through aldehyde deformylation.

Recently, our group reported several copper(II)-alkylperoxo complexes with bispidine ligand systems and studied their reactivity in aldehyde deformylation reactions with substrates. ${ }^{199}$ In contrast to the previously reported nucleophilic addition at the carbonyl carbon, these bispidineligated complexes undergo electrophilic $\alpha$-hydrogen abstraction as evidenced from KIE experiments. The effect of steric bulk on the reactivity of these complexes was studied and it was shown that with the increase in the steric bulk around the metal centre, there is a decrease in the reaction rates for the aldehyde deformylation reactions.

Recently, aldehyde deformylation by a mononuclear copper(II)alkylperoxo complex was reported by Cho et al. ${ }^{200} \mathrm{~A}$ positive Hammett value of 2.3(3) for the reaction of the copper(II)alkylperoxo complex with para-substituted benzaldehyde suggested nucleophilic character of the complex. Further investigations in the presence of a redox-inactive metal ions showed that the nucleophilic reactivity was enhanced with the addition of redox-inactive metal ions $\left(\mathrm{M}^{3+}=\mathrm{La}^{3+}, \mathrm{Yb}^{3+}, \mathrm{Y}^{3+}, \mathrm{Sc}^{3+}\right)$. 
a)<smiles>O=C(Cl)c1ccccc1</smiles>
)<smiles></smiles><smiles>[CH]OOC(C)(C(=O)CCl)c1ccccc1</smiles><smiles>O=C(OO[C]1CCCCC1)c1ccccc1</smiles><smiles>C=CC=CCCCCCCCCCCOC(=O)c1ccccc1</smiles>

b)<smiles>[R]C([R])([R])[C+](CC[O+]O[Si])O[CH]</smiles><smiles>[R]C([R])([R])C(O[O-])OO[Si]</smiles><smiles></smiles>

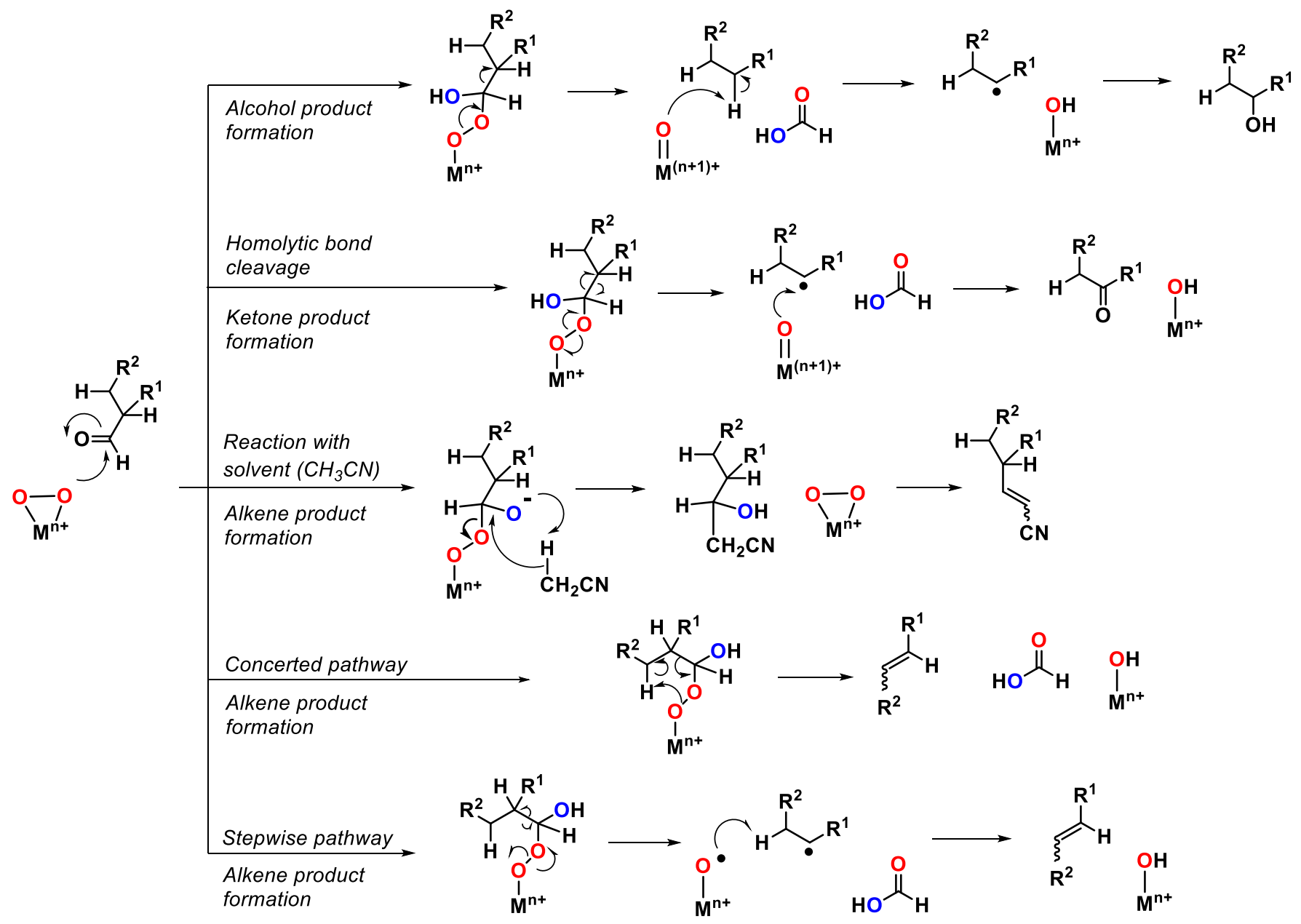




\section{Mechanistic insights into aldehyde deformylation by biomimetic model systems}

Mechanistic studies for aldehyde deformylation reactions catalysed by non-heme metal-dioxygen complexes have been extensively investigated in the past few decades. Often the reactions proceed via activated dioxygen adducts on metal complexes such as metal(III)-peroxo, metal(III)-hydroperoxo, metal(III)-alkylperoxo intermediates, or metal(II)-superoxo. Most of these catalytic intermediates are capable of reacting with aldehydes through an oxidative deformylation reaction. The commonly proposed mechanism for these reactions is a nucleophilic pathway, in which the oxygen atom attacks the carbonyl carbon leading to deformylated products, Scheme 21. ${ }^{161-164,175-177,196}$ Such mechanism has also been proposed for biological systems that perform aldehyde deformylation reactions. ${ }^{15,36}$ In general, the nucleophilic addition mechanism is the consensus mechanism for biomimetic aldehyde deformylation reactions and many examples have been reported of mechanistic studies.

However, recently alternative mechanistic routes for oxidative aldehyde deformylation reactions have been proposed based on a combination of experimental and computational studies.
These reactions appear to depend not only on the nature of the substrate, but also on the ligand structure of the non-heme metal complexes. In particular, our groups have studied the reaction of a manganese(III)-peroxo complex of a bispidine ligand with 2-PPA and proposed that the aldehyde deformylation reaction proceeds through a hydrogen atom abstraction instead of a nucleophilic addition reaction. ${ }^{166-169}$ The experimental findings were supported fully by computational modelling of structure and reactivity and suggest the feasibility of an electrophilic pathway over the nucleophilic attack.

Experimentally, upon the addition of 2-PPA to the Mn (III)peroxo complex, the intermediate decayed immediately to produce acetophenone. To establish whether the reaction proceeds through a nucleophilic pathway, 2-Me-2-PPA was used as a mechanistic probe. Addition of 2-Me-2-PPA to the peroxo complex did not produce any deformylated product. To examine whether an alternative mechanistic pathway was possible initiating with a hydrogen atom abstraction from the $\alpha$ position, $\alpha-\left[D_{1}\right]-P P A$ was added to the peroxo complex resulting in the formation of the deformylated products. These kinetic studies confirm that the manganese-peroxo complex reacts with 2-PPA via a hydrogen atom abstraction from the $\alpha$ position with a KIE of 5.4

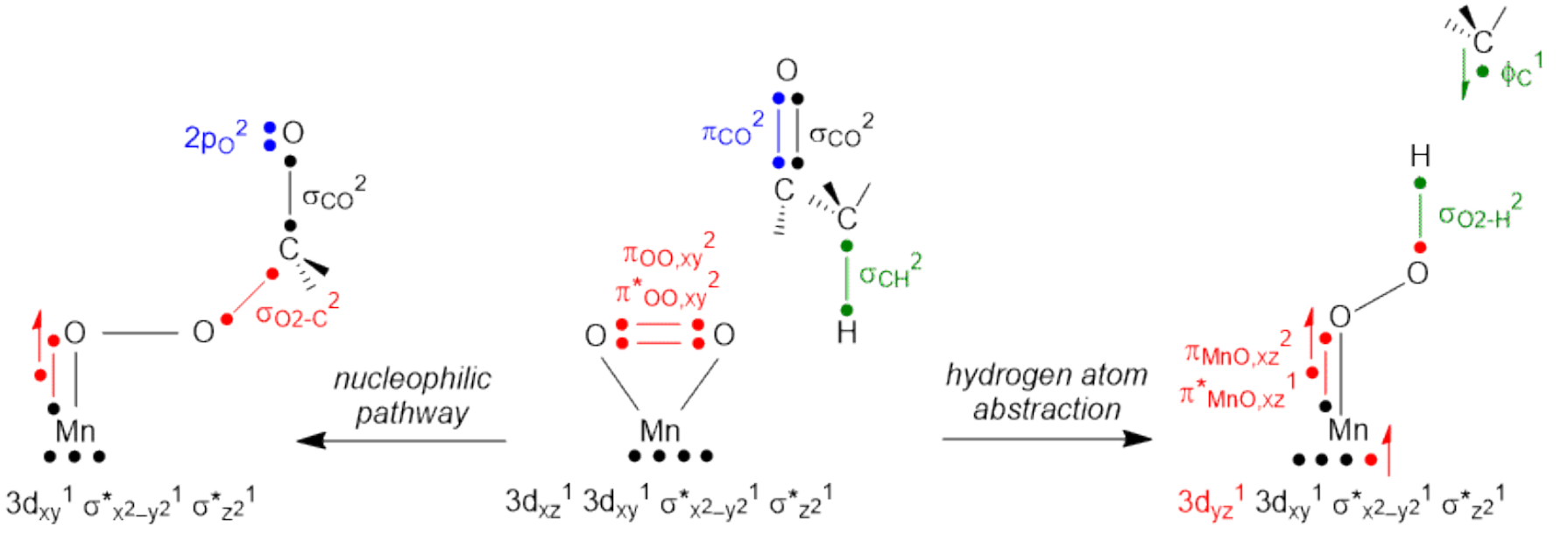

$$
\Delta \mathrm{E}_{\text {nucl }}^{\ddagger}=\mathrm{E}_{\pi(\mathrm{C}-\mathrm{O})}+\mathrm{E}_{\pi / \pi^{*} \mathrm{OO}, \mathrm{xy}}
$$$$
\Delta E^{\ddagger}{ }_{H A T}=E_{\sigma(C-H)}+E_{\pi / \pi^{*} O O, x y}+E_{e x c, M n}
$$

$$
{ }^{5} I_{\text {nucl }} \quad{ }^{5} \mathrm{Re}_{\text {ald }}
$$

Fig. 4. Valence bond molecular orbital diagram explaining the electronic differences for nucleophilic attack versus hydrogen atom abstraction as initial step in aldehyde deformylation mechanisms by biomimetic manganese(III)-peroxo complexes. 
To support this novel mechanistic pathway, a series of detailed computational studies were performed. ${ }^{167,168}$ The calculated energies of the transition states corresponding to hydrogenatom abstraction from the $\alpha$-position and the nucleophilic addition on the carbonyl group of aldehydes reveal that the hydrogen-atom abstraction pathway is favourable as its energy barrier is lower than that of the nucleophilic pathway. A detailed theoretical analysis and additional comparative experimental data involving several isomeric bispidine manganese(III)-peroxo complexes were brought to the forefront in support of this mechanism. The manganese(III)peroxo intermediate abstracts an $\alpha$-hydrogen-atom from the aldehyde and forms a manganese(II)-hydroperoxo along with a radical intermediate. Then the hydrogen-atom is bounced back to the aldehyde substrate to produce the enol form of the substrate along with regeneration of the manganese(III)-peroxo complex. This enol form of the substrate is less stable than that of the keto form. Thus, once the substrate is in the enol form, the manganese(III)-peroxo complex attacks the olefin bond of the substrate via a nucleophilic route to form another radical intermediate. This radical intermediate reacts through an $\mathrm{O}-\mathrm{O}$ bond cleavage to form a manganese-oxo and an epoxide which is a highly exothermic and irreversible process. Thereafter, the manganese(III)-oxo abstracts a hydrogen atom from alcohol group of the epoxide to form a manganese(II)-hydroxo and a radical. Finally, the subsequent rebound of $\mathrm{OH}$ group results in the opening of epoxide ring and $\mathrm{C}-\mathrm{C}$ bond cleavage, which leads to the formation of methylphenylketone and formic acid. Also, a detailed kinetic study revealed that the aldehyde deformylation reactions proceed through the hydrogen atom abstraction pathway, when 2-PPA was added to a couple of bispidine $\mathrm{Cu}(\mathrm{II})$-alkylperoxo complexes to produce acetophenone. It has been demonstrated that the rate of the reaction decreased with the increase in steric bulk around the metal centres.

The computational studies analysed the electronic differences between the nucleophilic and electrophilic proposed mechanisms of aldehyde deformylation by biomimetic manganese(III)-peroxo complexes. ${ }^{167,168}$ In particular, a detailed valence bond analysis on the molecular orbitals that are broken and formed in the rate-determining step was performed. These valence bond analyses have been used previously to explain trends in reactivity patterns and the origin of the chemoselectivity of oxidants and enzymes. ${ }^{201-206} \mathrm{Fig}$. 4 gives a valence bond description of the molecular orbitals in the reactants that change upon either nucleophilic attack by an aldehyde or hydrogen atom abstraction from an aldehyde $\mathrm{C}-\mathrm{H}$ bond. This figure displays electrons as a dot and a chemical bond as a line in between two dots. Thus, in the manganese(III)peroxo complex the electronic configuration is $3 d_{x z}{ }^{1} 3 d_{x y}{ }^{1} \pi_{00, x y}{ }^{2}$ $\pi^{*}{ }_{\mathrm{oo}, \mathrm{xy}}{ }^{1} \sigma^{*}{ }_{\mathrm{xz}-\mathrm{y} 2}{ }^{1} \sigma^{*}{ }_{\mathrm{z2}}{ }^{1}$ in the quintet spin state. Two metal $3 \mathrm{~d}$ orbitals $\left(3 d_{x z}\right.$ and $\left.3 d_{x y}\right)$ are essentially atomic orbitals with little interactions with ligands. In the $x y$-plane, the peroxo orbitals are occupied by four electrons as $\pi_{00, x y}{ }^{*} \pi_{00, x y}{ }^{2}$. In the reactant complex $\left({ }^{5} \mathbf{R e}_{\text {ald }}\right)$ there are two electrons in the substrate $\mathrm{C}-\mathrm{H}$ bond in the $\sigma_{\mathrm{CH}}$ orbital and four electrons in the carbonyl bond $\left(\sigma_{\mathrm{CO}}^{2} \pi_{\mathrm{CO}^{2}}\right)$
As follows from Fig. 4 the nucleophilic and hydrogen atom abstraction pathways have different relevant orbitals that determine the differences in relative barrier heights. For the hydrogen atom abstraction, the initial barrier height will be determined by the $\mathrm{C}-\mathrm{H}$ orbital of the substrate that is broken $\left(\sigma_{\mathrm{CH}}\right)$. However, upon hydrogen atom abstraction the manganese(III)-side-on peroxo changes to an end-on hydroperoxo structure, which has significant effects on the molecular orbitals as well. In particular, the peroxo orbitals $\pi_{\mathrm{Oo}, \mathrm{xy}}$ and $\pi^{*}{ }_{\mathrm{oo}, \mathrm{xy}}$ break and the electrons form new molecular orbitals: two of those pair up with the $3 d_{x z}$ orbital to form a three-electron bond $\pi_{\mathrm{MnO}, \mathrm{xz}^{2}} \pi^{*}{ }_{\mathrm{MnO}, \mathrm{xz}^{1}}$, a third electron is promoted into the empty $3 d_{y z}$ orbital, while the fourth pairs up with the electron of the hydrogen atom to form the $\sigma_{\mathrm{O} 2-\mathrm{H}}$ orbital. It was established; 168 therefore, that the hydrogen atom abstraction barrier should correlate with the energy to break the $\sigma_{C H}$ orbital in the substrate $\left(E_{\sigma(C-H)}\right)$, the energy to break the peroxo bond in the $x y$-plane $\left(\mathrm{E}_{\pi / \pi^{*} \mathrm{OO}, \mathrm{xy}}\right)$ and the promotion of an electron into the $3 d_{x y}$ orbital $\left(E_{\text {exc, } M n}\right)$.

By contrast, in the nucleophilic pathway the $\pi$-bond of the carbonyl group of the substrate is broken $\left(\pi_{\mathrm{co}}\right)$ and the two electrons move to the oxygen atom. At the same time the $\pi / \pi^{*}$ orbitals in the xy-plane of the peroxo group are broken and two of those electrons move into the newly formed $\mathrm{C}-\mathrm{O}$ bond, while the other two electrons pair up with the $3 d_{x z}$ electron to form the three-electron bond for the $\mathrm{Mn}-\mathrm{O}$ interaction. As such the nucleophilic transition state will be determined by the energy to break the $\pi$-bond in the carbonyl group of the aldehyde and the reorganization of the peroxo $\pi$ and $\pi^{*}$ orbitals in the $x y$ plane.

The valence bond modelling showed that this particular manganese(III)-peroxo complex with bispidine ligand requires relatively little energy to reorganize its molecular orbitals to break a tertiary or secondary $\mathrm{C}-\mathrm{H}$ bond of an aldehyde substrate that is competitive with a nucleophilic pathway. These orbital reorganization energies highlighted in Fig. 4 are strongly dependent on the electron-donating and electron-withdrawing power of the ligand bound to the metal and hence changing the ligand may trigger a nucleophilic preference over an electrophilic reaction mechanism for aldehyde deformylation.

\section{Conclusions}

Aldehyde deformylation is a versatile process in biology and many examples have been created and tested in organic and bioinorganic chemistry. A broad scale of different chemical reaction mechanisms for aldehyde deformylation is seen and reviewed in this paper. Although the commonly accepted mechanism relates to a nucleophilic type pathway in recent years examples have been published on alternative electrophilic mechanisms including ones that start with a rate-determining hydrogen atom abstraction. Further studies are undergoing in our groups to gain more detailed understanding into aldehyde deformylation reactions and whether they really proceed through a nucleophilic reaction mechanism or whether the electrophilic mechanism is more common. There is still much to 
explore on the mechanistic features and applicability of the aldehyde deformylation processes.

\section{Conflicts of interest}

There are no conflicts to declare.

\section{Acknowledgements}

CVS acknowledges the Department of Science and Technology (DST), Science and Engineering Research Board (SERB), India, for the research grant CRG/2019/000387. SPdV and CVS jointly thank the British Council and the DST for the UK-India Education and Research Initiative (UKIERI) grant (DST/INT/UK/P151/2017). CVS also recognizes SPARC (Ministry of Human Resource Development), India (SPARC/2018-2019/P153/SL) and DST-DAAD (DST/INT/DAAD/P-10/2019) for funding. GM is grateful to DST-SERB for financial assistance.

\section{Notes and references}

1 T. Patra, S. Manna and D. Maiti, Angew. Chem. Int. Ed., 2011 50, 12140.

2 M. Sono, M. P. Roach, E. D. Coulter and J. H. Dawson, Chem. Rev., 1996, 96, 2841.

3 P. R. Ortiz de Montellano, Ed., Cytochrome P450: Structure, Mechanism and Biochemistry, $3^{\text {rd }}$ Ed., Kluwer Academic/Plenum Publishers, New York, 2005.

4 A. W. Munro, H. M. Girvan and K. J. McLean, Nat. Prod. Rep., 2007, 24, 585

5 K. M. Kadish, K. M. Smith and R. Guilard, Eds., Handbook of Porphyrin Science, World Scientific Publishing Co., New Jersey, 2010.

6 T. D. H. Bugg, Curr. Opin. Chem. Biol., 2001, 5, 550.

7 S. P. de Visser and D. Kumar (Eds.) Iron-containing enzymes: Versatile catalysts of hydroxylation reactions in nature, Royal Society of Chemistry Publishing, Cambridge (UK), 2011.

8 D. R. Nelson, L. Koymans, T. Kamataki, J. J. Stegeman, R. Feyereisen, D. J. Waxman, M. R. Waterman, O. Gotoh, M. J. Coon, R. W. Estabrook, I. C. Gunsalus and D. W. Nebert, Pharmacognetics, 1996, 6, 1.

9 M. Merkx, A. D. Kopp, M. H. Sazinsky, J. L. Blazyk, J. Muller and S. J. Lippard, Angew. Chem. Int. Ed, 2001, 40, 2782.

10 B. Cascella and L. M. Mirica, Biochemistry, 2012, 51, 8699.

11 P. Liu, K. Murakami, T. Seki, X. He, S. M. Yeung, T. Kuzuyama, H. Seto and H. Liu, J. Am. Chem. Soc., 2001, 123, 4619.

12 P. Liu, A. Liu, F. Yan, M. D. Wolfe, J. D. Lipscomb and H. Liu, Biochemistry, 2003, 42, 11577.

13 A. D. N. Vaz, E. S. Roberts and M. J. Coon, J. Am. Chem. Soc. 1991, 113, 5887

14 V. J. Feron, H. P. Til, F. de Vrijer, R. A. Woutersen, F. R. Cassee and P. J. van Bladeren, Mutat. Res., 1991, 259, 363.

15 E. S. Roberts, A. D. N. Vaz and M. J. Coon, Proc. Natl. Acad. Sci. USA, 1991, 88, 8963.

16 K. R. Korzekwa, W. F. Trager, J. Mancewicz and Y. Osawa, J. Steroid Biochem. Molec. Biol, 1993, 44, 367.

17 Y. Watanabe and Y. Ishimura, J. Am. Chem. Soc., 1989, 111, 8047.

18 Y. Watanabe and Y. Ishimura, J. Am. Chem. Soc., 1989, 111 410.

19 P. A. Cole and C. H. Robinson, Proc. Natl. Acad. Sci. USA, 1990, 87, 2999.
20 D. E. Stevenson, J. N. Wright and M. Akhtar, J. Chem. Soc. Perkin Trans., 1988, 1, 2043.

21 M. Akhtar, M. R. Calder, D. L. Corina and J. N. Wright, Biochem. J., 1982, 201, 569.

22 A. Schirmer, M. A. Rude, X. Li, E. Popova and S. B. del Cardayre, Science, 2010, 329, 559.

23 D. M. Warui, N. Li, H. Nørgaard, C. Krebs, J. M. Bollinger Jr and S. J. Booker, J. Am. Chem. Soc., 2011, 133, 3316.

24 N. Li, W. Chang, D. M. Warui, S. J. Booker, C. Krebs and J. M. Bollinger Jr, Biochemistry, 2012, 51, 7908.

25 N. Li, H. Nørgaard, D. M. Warui, S. J. Booker, C. Krebs and J. M. Bollinger Jr, J. Am. Chem. Soc., 2011, 133, 6158.

26 B. Meunier, S. P. de Visser and S. Shaik, Chem. Rev., 2004, 104 3947.

27 I. G. Denisov, T. M. Makris, S. G. Sligar and I. Schlichting, Chem Rev., 2005, 105, 2253.

28 P. R. Ortiz de Montellano, Chem. Rev., 2010, 110, 932.

29 F. Ogliaro, N. Harris, S. Cohen, M. Filatov, S. P. de Visser and S Shaik, J. Am. Chem. Soc., 2000, 122, 8977.

30 S. P. de Visser and S. Shaik, J. Am. Chem. Soc., 2003, 125, 7413

31 D. Kumar, B. Karamzadeh, G. N. Sastry and S. P. de Visser, J. Am. Chem. Soc., 2010, 132, 7656.

32 D. Kumar, R. Latifi, S. Kumar, E. V. Rybak-Akimova, M. A Sainna and S. P. de Visser, Inorg. Chem., 2013, 52, 7968.

33 F. G. Cantú Reinhard, M. A. Sainna, P. Upadhyay, G. A. Balan, D. Kumar, S. Fornarini, M. E. Crestoni and S. P. de Visser, Chem. Eur. J., 2016, 22, 18608.

34 E. A. Thompson and P. K. Siiteri, J. Biol. chem., 1974, 249, 5364

35 E. A. Thompson and P. K. Siiteri, J. Biol. Chem., 1974, 249, 5373.

36 Y. Goto, S. Wada, I. Morishima and Y. Watanabe, J. Inorg. Biochem., 1998, 69, 241.

37 M. R. A. Blomberg, T. Borowski, F. Himo, R.-Z. Liao and P. E. M Siegbahn, Chem. Rev., 2014, 114, 3601.

38 S. Shaik, D. Kumar, S. P. de Visser, A. Altun and W. Thiel, Chem Rev., 2005, 105, 2279.

39 S. Shaik, S. Cohen, Y. Wang, H. Chen, D. Kumar and W. Thiel Chem. Rev., 2010, 110, 949.

40 S. P. de Visser, M. G. Quesne, B. Martin, P. Comba and U. Ryde, Chem. Commun., 2014, 50, 262.

41 M. G. Quesne, T. Borowski and S. P. de Visser, Chem Eur. J. 2016, 22, 2562.

42 J. C. Hackett, R. W. Brueggemeier and C. M. Hadad, J. Am Chem. Soc., 2005, 127, 5224.

43 K. Sen and J. C. Hackett, J. Am. Chem. Soc., 2010, 132, 10293.

44 X. Huang and J. T. Groves, Chem. Rev., 2018, 118, 2491.

45 M. T. Green, Curr. Opin. Chem. Biol., 2009, 13, 84.

46 P. Rydberg, U. Ryde and L. Olsen, J. Chem. Theory Comput. 2008, 4, 1369.

47 D. Li, Y. Wang, C. Yang and K. Han, Dalton Trans., 2009, 38, 291.

48 V. A. Dixit, J. Warwicker and S. P. de Visser, Chem. Eur. J., 2020, 26, 15270

49 J. Rittle and M. T. Green, Science, 2010, 330, 933.

50 S. Louka, S. M. Barry, D. J. Heyes, M. Q. E. Mubarak, H. S. Ali, L. M. Alkhalaf, A. W. Munro, N. S. Scrutton, G. L. Challis and S. P. de Visser, J. Am. Chem. Soc., 2020, 142, 15764.

51 B. Krámos and J. Oláh, J. Phys. Chem. B, 2014, 118, 390.

52 B. Krámos and J. Oláh, Struct. Chem., 2015, 26, 279.

53 M. Daroch, S. Geng and G. Wang, Appl. Energy, 2013, 102 1371.

54 I. Machado and S. Atsumi, J. Biotechnol., 2012, 162, 50

55 M. A. Rude and A. Schirmer, Curr. Opin. Microbiol., 2009, 12, 274.

56 M. A. Rude, T. S. Baron, S. Brubaker, M. Alibhai, S. B. Del Cardayre and A. Schirmer, Appl. Environ. Microbiol., 2011, 77 1718. 
57 A. Dennig, M. Kuhn, S. Tassoti, A. Thiessenhusen, S. Gilch, T. Bülter, T. Haas, M. Hall and K. Faber, Angew. Chem. Int. Ed. 2015, 54, 8819.

58 J. L. Grant, C. H. Hsieh and T. M. Makris, J. Am. Chem. Soc., 2015, 137, 4940.

59 A. W. Munro, K. J. McLean, J. L. Grant and T. M. Makris, Biochem. Soc. Trans., 2018, 46, 183.

60 M. Pickl, S. Kurakin, F. G. Cantú Reinhard, P. Schmid, A Pöcheim, C. K. Winkler, W. Kroutil, S. P. de Visser and K. Faber, ACS Catal., 2019, 9, 565.

61 A. S. Faponle, M. G. Quesne and S. P. de Visser, Chem. Eur. J., 2016, 22, 5478.

62 A. S. Chowdhury, H. S. Ali, A. S. Faponle and S. P. de Visser, Phys. Chem. Chem. Phys., 2020, 22, 27178.

63 A. Schirmer, M. A. Rude, X. Li, E. Popova and S. B. del Cardayre, Science, 2010, 329, 559.

64 D. M. Warui, N. Li, H. Nørgaard, C. Krebs, J. M. Bollinger Jr and S. J. Booker, J. Am. Chem. Soc., 2011, 133, 3316.

65 N. Li, W. Chang, D. M. Warui, S. J. Booker, C. Krebs and J. M. Bollinger Jr, Biochemistry, 2012, 51, 7908.

66 N. Li, H. Nørgaard, D. M. Warui, S. J. Booker, C. Krebs and J. M. Bollinger Jr, J. Am. Chem. Soc., 2011, 133, 6158.

67 K. G. Aukema, T. M. Makris, S. A. Stoian, J. E. Richman, E. Münck, J. D. Lipscomb and L. P. Wackett, ACS Catal., 2013, 3, 2228.

68 D. Das, B. Ellington, B. Paul and E. N. G. Marsh, ACS Chem. Biol., 2014, 9, 570.

69 Q. Wang, X. Huang, J. Zhang, X. Lu, S. Li and J.-J. Li, Chem. Commun., 2014, 50, 4299.

70 J. Wang and K. Zhu, Curr. Opin. Biotechnol., 2018, 50, 11.

71 M. E. Pandelia, N. Li, H. Nørgaard, D. M. Warui, L. J. Rajakovich, W. C. Chang, S. J. Booker, C. Krebs and J. M. Bollinger Jr, J. Am. Chem. Soc., 2013, 135, 15801.

72 M. W. Waugh and E. N. G. Marsh, Biochemistry, 2014, 53, 5537.

73 B. E. Eser, D. Das, J. Han, P. R. Jones and E. N. G. Marsh, Biochemistry, 2012, 50, 10743.

74 D. Das, B. E. Eser, J. Han, A. Sciore and E. N. G. Marsh, Angew. Chem. Int. Ed., 2011, 50, 7148.

75 J. Zhang, X. Lu and J. J. Li, Biotechnology for Biofuels, 2013, 6, 86

76 B. Khara, N. Menon, C. Levy, D. Mansell, D. Das, E. N. G. Marsh, D. Leys and N. S. Scrutton, ChemBioChem., 2013, 14, 1204.

77 H. M. Berman, J. Westbrook, Z. Feng, G. Gilliland, T. N. Bhat, H. Weissig, I. N. Shindyalov and P. E. Bourne, Nucl. Acids Res., 2000, 28, 235.

78 B. C. Buer, B. Paul, D. Das, J. A. Stuckey and E. N. G. Marsh, ACS Chem. Biol., 2014, 9, 2584.

79 C. Jia, M. Li, J. Li, J. Zhang, H. Zhang, P. Cao, X. Pan, X. Lu and W. Chang, Protein Cell, 2015, 6, 55.

80 Y. Hayashi, F. Yasugi and M. Arai, PLoS One, 2015, 10, 1-14.

81 H. Kigoshi, Y. Imamura, A. Sawada, H. Niwa and K. Yamada, Bull. Chem. Soc. Jpn., 1991, 64, 3735.

82 J. Wengel and E. B. Pedersen, Synthesis, 1991, 451.

83 D. P. Chakraborty, Biochemical and medicinal properties of carbazole alkaloids and related compounds. In The Alkaloids, Chemistry and Pharmacology, G. A. Cordell (Ed.); Academic Press: San Diego, 1993; Vol. 44, Chapter 4, pp 257-364.

84 H.-J. Knolker and K. R. Reddy, Chem. Rev., 2002, 102, 4303.

85 R. Pathak, J. M. Nhlapo, S. Govender, J. P. Michael, W. A. L. van Otterlo and C. B. de Koning, Tetrahedron, 2006, 62, 2820

86 H. Oishi, T. Noto, H. Sasaki, K. Suzuki, T. Hayashi, H. Okazaki and K. Ando, J. Antibiotics, 1982, 4, 391.

87 H. Sasaki, H. Oishi, T. Hayashi, I. Matsuura, K. Ando and M. Sawada, J. Antibiotics, 1982, 4, 396.

88 T. Noto, S. Miyakawa, H. Oishi, H. Endo and H. Okazaki, J. Antibiotics, 1982, 4, 401.
89 S. Miyakawa, K. Suzuki, T. Noto, Y. Harada and H. Okazaki, J. Antibiotics, 1982, 4, 411.

90 C.-L. J. Wang and J. M. Salvino, Tetrahedron Lett., 1984, 25 46, 5243.

91 L. Kremer, J. D. Douglas, A. R. Baulard, C. Morehouse, M. R. Guy, D. Alland, L. G. Dover, J.H. Lakey, W. R. Jr. Jacobs, P. J. Brennan, D. E. Minnikin and G. S. Besra, J. Biol. Chem., 2000, 275, 16857.

92 S. M. Sakya, M. Suarez-Contreras, J. P. Dirlam, T. N. O’Connell, S. F. Hayashi, S. L. Santoro, B. J. Kamicker, D. M. George and C. B. Ziegler, Bioorg. Med. Chem. Lett., 2001, 11, 2751.

93 J. M. McFadden, G. L. Frehywot and C. A. Townsend, Org. Lett., 2002, 4, 3859.

94 S. J. Senior, P. A. Illarionov, S.S. Gurcha, I. B. Campbell, M.L. Schaeffer, D. E. Minnikin and G. S. Besra, Bioorg. Med. Chem. Lett., 2003, 13, 3685.

95 S. M. Jones, J. E. Urch, M. Kaiser, R. Brun, J. L. Harwood, C. Berry and I. H. Gilbert, J. Med. Chem., 2005, 48, 5932.

96 J. M. McFadden, S. M. Medghalchi, J. N. Thupari, M.L. Pinn, A Vadlamudi, K. I. Miller, F. P. Kuhajda and C. A. Townsend, J. Med. Chem., 2005, 48, 946.

97 A. Kamal, A. A. Shaik, R. Sinha, J. S. Yadav and S. K. Arora, Bioorg. Med. Chem. Lett., 2005, 15, 1927.

98 P. Kim, Y.-M. Zhang, G. Shenoy, Q.-A. Nguyen, H. I. Boshoff, U. H. Manjunatha, M. Goodwin, J. Lonsdale, A. C. Price, D. J. Miller, K. Duncan, S. W. White, C. O. Rock, C. E. Barry III and C. S. Dowd, J. Med. Chem., 2006, 49, 159.

99 P. Kim, C. E. Barry, III and C. S. Dowd, Tetrahedron Letters 2006, 47, 3447

100 T. B. Poulsen and K. A. Jørgensen, Chem. Rev., 2008, 108 2903

101 G. Bartoli, G. Bencivenni and R. Dalpozzo, Chem. Soc. Rev., 2010, 39, 4449

102 K. Sun, S. Liu, P. M. Bec and T. G. Driver, Angew. Chem. Int Ed., 2011, 50, 1702.

103 A. Brancale and R. Silvestri, Med. Res. Rev., 2007, 27, 209.

104 A. J. Kochanowska-Karamyan and M. T. Hamann, Chem Rev., 2010, 110, 4489.

105 I. S. Chikvaidze, S. A. Samsoniya, T. G. Narindoshvili and N. V. Kobakhidze, Chem. Heterocycl. Comp., 2000, 36, 1346.

106 A. Hazra, P. Paira, K. B. Sahu, S. Banerjee and N. B. Mondal, Catal. Commun., 2008, 9, 1681.

107 T. Odagami, T. Tsuda, Y. Kogami, H. Kouji and Y. Okada, Chem. Pharm. Bull., 2009, 57, 211.

108 R. R. Yadav, N. Battini, R. Mudududdla, J. B. Bharate, N Muparappu, S. B. Bharate and R. A. Vishwakarma, Tetrahedron Lett., 2012, 53, 2222.

109 J. Yu, Z. Li and W. Su, Synth. Commun., 2013, 43, 361.

110 Y. Jung and I. Kim, Org. Lett. 2015, 17, 4600.

111 R. F. Heck, J. Am. Chem. Soc., 1968, 90, 5518.

112 R. F. Heck and J. P. Nolley, J. Org. Chem., 1972, 37, 2320.

113 H. A. Dieck and R. F. Heck, J. Am. Chem. Soc., 1974, 96 1133.

114 K. Sonogashira, Y. Tohda and N. Hagihara, Tetrahedron Lett., 1975, 16, 4467.

115 A. O. King, N. Okukado and E.-I. Negishi, J. Chem. Soc. Chem. Commun., 1977, 683.

116 N. Miyaura, K. Yamada and A. Suzuki, Tetrahedron Lett., 1979, 20, 3437

117 J. H. Kirchhoff, M. R Netherton, I. D. Hill and G. C. Fu, J. Am. Chem. Soc., 2002, 124, 13662.

118 M. Eckhardt and G. C. Fu, J. Am. Chem. Soc., 2003, 125 13642

119 J. E. Milne and S. L. Buchwald, J. Am. Chem. Soc., 2004 126, 13028

120 B. Saito and G. C. Fu, J. Am. Chem. Soc., 2007, 129, 9602

121 D.-H. Lee, H. Qiu, M.-H. Cho, I.-M. Lee and M.-J. Jin Synlett., 2008, 1657. 
122 S. Sase, M. Jaric, A. Metzger, V. Malakhov and P. Knochel, J. Org. Chem., 2008, 73, 7380.

123 E. Glinis, E. Malamidou-Xenikaki, H. Skouros, S. Spyroudis and M. Tsanakopoulous, Tetrahedron, 2010, 66, 5786.

124 B. Tiwari, J. Zhang and Y. R. Chi, Angew. Chem. Int. Ed., 2002, 51, 1911.

125 A. Kipke, K.-U. Schöning, M. Yusubov and A. Kirschning, Eur. J. Org. Chem., 2017, 6906.

126 S. Liang, T. Kumon, R. A. Angnes, M. Sanchez, B. Xu and G. B. Hammond, Org. Lett., 2019, 21, 3848.

127 Q. Shuai, L. Yang, X. Guo, O. Baslé and C.-J. Li, J. Am. Chem. Soc., 2010, 132, 12212

128 M. L. N. Rao, B. S. Ramakrishna, J. Org. Chem., 2019, 84 5677.

129 M. Sivaraja, D. B. Goodin, M. Smith and B. M. Hoffman, Science, 1989, 245, 738.

130 J. E. Huyett, P. E.; Doan, R. Gurbiel, A. L. P. Houseman, M. Sivaraja, D. B. Goodin and B. M. Hoffman, J. Am. Chem. Soc., 1995, 117, 9033.

131 H. M. Girvan and A. W. Munro, Curr. Opin. Chem. Biol., 2016, 31, 136

132 X. Huang and J. T. Groves, Chem. Rev., 2018, 118, 2491.

133 J. C. Price, E. W. Barr, B. Tirupati, J. M. Bollinger Jr and C. Krebs, Biochemistry, 2003, 42, 7497.

134 D. A. Proshlyakov, T. F. Henshaw, G. R. Monterosso, M. J. Ryle and R. P. Hausinger, J. Am. Chem. Soc., 2004, 126, 1022.

135 J. M. Bollinger Jr, J. C. Price, L. M. Hoffart, E. W. Barr and C. Krebs, Eur. J. Inorg. Chem., 2005, 4245.

136 D. Galonić Fujimori, E. W. Barr, M. L. Matthews, G. M. Koch, J. R. Yonce, C. T. Walsh, J. M. Bollinger Jr, C. Krebs and P. J. Riggs-Gelasco, J. Am. Chem. Soc., 2007, 129, 13408.

137 S. P. de Visser, Angew. Chem. Int. Ed., 2006, 45, 1790.

138 S. Shaik, H. Chen, D. Janardanan, Nat. Chem., 2011, 3, 19.

139 S. P. de Visser, J. Am. Chem. Soc., 2010, 132, 1087.

140 E. G. Kovaleva, M. B. Neibergall, S. Chakrabarty and J. D. Lipscomb, Acc. Chem. Res., 2007, 40, 475.

141 Y. Watanabe, H. Nakajima and T. Ueno, Acc. Chem. Res., 2007, 40, 554

142 S. P. de Visser, J.-U. Rohde, Y.-M. Lee, J. Cho and W. Nam, Coord. Chem. Rev., 2013, 257, 381.

143 T. Ohta, J.-G. Liu and Y. Naruta, Coord. Chem. Rev., 2013 257, 407

144 W. Nam, Y.-M. Lee and S. Fukuzumi, Acc. Chem. Res., 2018, 51, 2014

145 M. Costas, M. P. Mehn, M. P. Jensen and L. Que Jr., Chem Rev., 2004, 104, 939.

146 M. M. Abu-Omar, A. Loaiza and N. Hontzeas, Chem. Rev., 2005, 105, 2227.

147 P. C. A. Bruijnincx, G. van Koten and R. J. M. Klein Gebbink, Chem. Soc. Rev., 2008, 37, 2716.

148 A. R. McDonald and L. Que Jr, Coord. Chem. Rev., 2013, 257, 414 .

149 K. Ray, F. F. Pfaff, B. Wang, W. Nam, J. Am. Chem. Soc., 2014, 136, 13942.

150 S. Rana, R. Haque, G. Santosh and D. Maiti, Inorg. Chem., 2013, 52, 2927.

151 S. Rana, B. Pandey, A. Dey, R. Haque, G. Rajaraman and D. Maiti, ChemCatChem, 2016, 8, 3367.

152 M. Q. E. Mubarak, E. F. Gérard, C. F. Blanford, S. Hay and S. P. de Visser, ACS Catal., 2020, 10, 14067.

153 K. Barnese, E. B. Gralla, D. E. Cabelli and J. S. Valentine, J. Am. Chem. Soc., 2008, 130, 4604.

154 R. Tagore, H. Chen, R. H. Crabtree and G. W. Brudvig, J. Am. Chem. Soc., 2006, 128, 9457.

155 A. J. Wu, J. E. Penner-Hahn and V. L. Pecoraro, Chem. Rev., 2004, 104, 903.

156 K. D. Koehntop, J. P. Emerson and L. Que Jr, J. Biol. Inorg. Chem., 2005, 10, 87.
157 W. A. Gunderson, A. I. Zatsman, J. P. Emerson, E. R. Farquhar, L. Que, Jr, D. Lipscomb and M. P. Hendrich, J. Am. Chem. Soc., 2008, 130, 14465.

158 T. Borowski, A. Bassan, N. G. J. Richards and P. E. M. Siegbahn, J. Chem. Theory Comput., 2005, 1, 686.

159 O. Opaleye, R.-S. Rose, M. M. Whittaker, E. J. Woo, J. W. Whittaker and R. W. Pickersgill, J. Biol. Chem., 2006, 281, 6428.

160 X. C. Li, J. Li, P. E. M. Siegbahn, J. Phys. Chem. A., 2020, 124, 8011

161 M. S. Seo, J. Y. Kim, J. Annaraj, Y. Kim, Y. M. Lee, S. J. Kim J. Kim and W. Nam, Angew. Chem., Int. Ed., 2007, 46, 377.

162 J. Annaraj, J. Cho, Y. M. Lee, S. Y. Kim, R. Latifi, S. P. de Visser and W. Nam, Angew. Chem., Int. Ed., 2009, 48, 4150.

163 H. Kang, J. Cho, K. B. Cho, T. Nomura, T. Ogura and W. Nam, Chem. Eur. J., 2013, 19, 14119.

164 R. A. Geiger, S. Chattopadhyay, V. W. Day, T. A. Jackson, Dalton Trans., 2011, 40, 1707.

165 M. C. Denler, G. B. Wijeratne, D. B. Rice, H. E. Colmer, V. W. Day and T. A. Jackson, Dalton Trans., 2018, 47, 13442.

166 J. D. Parham, G. B. Wijeratne, J. R. Mayfield and T. A. Jackson, Dalton Trans., 2019, 48, 13034.

167 P. Barman, P. Upadhyay, A. S. Faponle, J. Kumar, S. S. Nag, D. Kumar, C. V. Sastri and S. P. de Visser, Angew. Chem. Int. Ed., 2016, 55, 11257.

168 F. G. Cantú Reinhard, P. Barman, G. Mukherjee, J. Kumar, D. Kumar, D. Kumar, C. V. Sastri and S. P. de Visser, J. Am. Chem. Soc., 2017, 139, 18328.

169 P. Barman, F. G. Cantú Reinhard, U. Bagha, D. Kumar, C. V. Sastri and S. P. de Visser, Angew. Chem. Int. Ed., 2019, 58, 10749.

170 G. Mukherjee and C. V. Sastri, Isr. J. chem., 2020, 60, 1032.

171 Z. Chen and G. Yin, Chem. Soc. Rev., 2015, 44, 1083.

172 W. J. Song, Y. O. Ryu, R. Song and W. Nam, J. Biol. Inorg Chem., 2005, 10, 294.

173 S. P. de Visser, Chem. Eur. J., 2006, 12, 8168.

174 J. Annaraj, Y. Suh, M. S. Seo, S. O. Kim and W. Nam, Chem. Commun., 2005, 4529.

175 M. J. Park, J. Lee, Y. Suh, J. Kim and W. Nam, J. Am. Chem. Soc., 2006, 128, 2630.

176 J. Cho, S. Jeon, S. A. Wilson, L. V. Liu, E. A. Kang, J. J. Braymer, M. H, Lim, B. Hedman, K. O. Hodgson, J. S. Valentine, E. I. Solomon and W. Nam, Nature, 2011, 478, 502.

177 S. Rat, S. Mènage, F. Thomas and V. Nivière, Chem. Commun., 2014, 50, 14213.

178 A. Shokri and L. Que Jr., J. Am. Chem. Soc., 2015, 137, 7686.

179 S. H. Bae, X.-X Li, M. S. Seo, Y.- M. Lee, S. Fukuzumi and W. Nam, J. Am. Chem. Soc., 2019, 141, 7675.

180 Y. Jo, J. Annaraj, M. S. Seo, Y. M. Lee, S. Y. Kim, J. Cho and W. Nam, J. Inorg. Biochem., 2008, 102, 2155.

181 J. Cho, R. Sarangi, H. Y. Kang, J. Y. Lee, M. Kubo, T. Ogura, E. I. Solomon and W. Nam, J. Am. Chem. Soc., 2010, 132, 16977.

182 W. Y. Tcho, B. Wang, Y. M. Lee, K. B. Cho, J. Shearer and W. Nam, Dalton Trans., 2016, 45, 14511.

183 Q. Zhang, A. B. Taylor, F. M. Bronston, J. D. Gorden and C. R. Goldsmith, Inorg. Chem., 2017, 56, 773.

184 B. Shin, Y. Park, D. Jeong and J. Cho, Chem. Commun., 2020, 56, 9449.

185 S. Z. Tasker, E. A. Standley and T. F. Jamison, Nature, 2014, 509, 299.

186 E. Richmond and J. Moran, Synthesis, 2018, 50, 499.

187 N. A. Harry, S. Saranya, S. M. Ujwaldev and G. Anilkumar, Catal. Sci. Technol., 2019, 9, 1726.

188 S. Hikichi, H. Okuda, Y. Ohzu and M. Akita, Angew. Chem. Int. Ed., 2009, 48, 188. 
189 J. Cho, R. Sarangi, J. Annaraj, S. Y. Kim, M. Kubo, T. Ogura, E. I. Solomon and W. Nam, Nat. Chem., 2009, 1, 568.

190 S. Hikichi, C. Kobayashi, M. Yoshizawa and M. Akita, Chem. Asian J., 2010, 5, 2086.

191 J. Kim, B. Shin, H. Kim, J. Lee, J. Kang, S. Yanagisawa, T. Ogura, H. Masuda, T. Ozawa and J. Cho, Inorg. Chem., 2015, 54, 6176.

192 C. Panda, A. Chandra, T. Corona, E. Andris, B. Pandey, S. Garai, N. Lindenmaier, S. Kunstner, E. R. Farquhar, J. Roithova, G. Rajaraman, M. Driess and K. Ray, Angew. Chem. Int. Ed., 2018, 57, 14883

193 S. Yun, N. Kwon, S. Kim, D. Jeong, T. Ohta and J. Cho, Inorg Chem. Front., 2019, 6, 2112

194 E. Theil, K. Raymond, in I. Bertini, H. B. Gray, S. J. Lippard and J. S. Valentine, Eds., Bioinorganic Chemistry, University Science Books, Mill Valley, 1994, pp. 1-35.

195 E. I. Solomon, D. E. Heppner, E. M. Johnston, J. W. Ginsbach, J. Cirera, M. Qayyum, M. T. Kieber-Emmons, C. H. Kjaergaard, R. G. Hadt, L. Tian, Chem. Rev., 2014, 114, 3659.

196 P. Pirovano, A. M. Magherusan, C. McGlynn, A. Ure, A. Lynes and A. R. McDonald, Angew. Chem. Int. Ed., 2014, 53 5946.

197 B. Kim, D. Jeong and J. Cho, Chem. Commun., 2017, 53 9328.

198 B. Kim, D. Jeong, T. Ohta and J. Cho, Commun Chem., 2019, 2, 81.

199 S. S. Nag, G. Mukherjee, P. Barman and C. V. Sastri, Inorg Chim. Acta, 2019, 485, 80.

200 B. Kim, S. Kim, T. Ohta and J. Cho, Inorg. Chem., 2020, 59 , 9938.

201 S. Shaik, D. Kumar and S. P. de Visser, J. Am. Chem. Soc., 2008, 130, 10128.

202 M. A. Sainna, S. Kumar, D. Kumar, S. Fornarini, M. E. Crestoni and S. P. de Visser, Chem. Sci., 2015, 6, 1516.

203 L. Ji, A. S. Faponle, M. G. Quesne, M. A. Sainna, J. Zhang, A. Franke, D. Kumar, R. van Eldik, W. Liu and S. P. de Visser, Chem. Eur. J., 2015, 21, 9083.

204 S. Ghafoor, A. Mansha and S. P. de Visser, J. Am. Chem. Soc., 2019, 141, 20278.

205 C. Colomban, A. H. Tobing, G. Mukherjee, C. V. Sastri, A. B. Sorokin and S. P. de Visser, Chem. Eur. J., 2019, 25, 14320

206 A. Timmins, M. G. Quesne, T. Borowski and S. P. de Visser, ACS Catal., 2018, 8, 8685.

207 M. G. Quesne, D. Senthilnathan, D. Singh, D. Kumar, $P$ Maldivi, A. B. Sorokin and S. P. de Visser, ACS Catal., 2016, 6, 2230. 
Org. Biomol. Chem.

\section{Table of Content Artwork:}

Aldehyde deformylation is one of the useful reactions in biology and organic syntheses and this review provides mechanistic insights into the same.

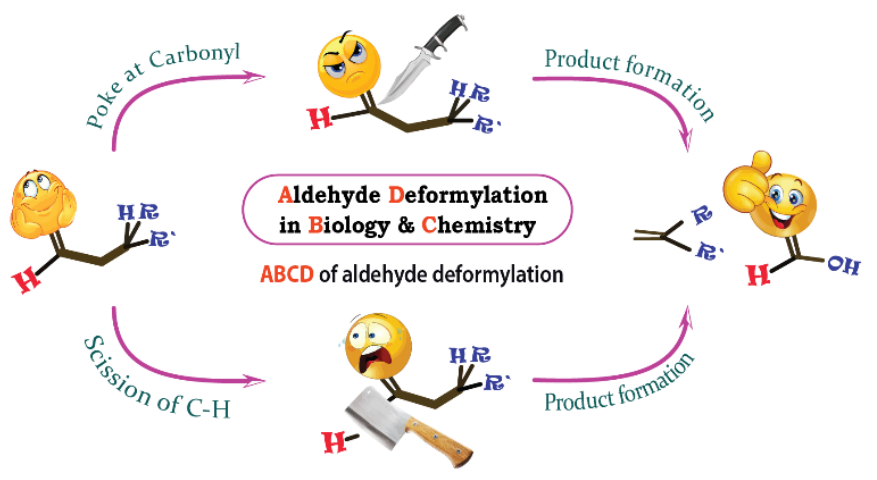




\section{Biographies:}

Umesh Kumar Bagha was born in Odisha, India in 1992. He did his graduation (2014) in Chemistry from Nayagarh Auto.

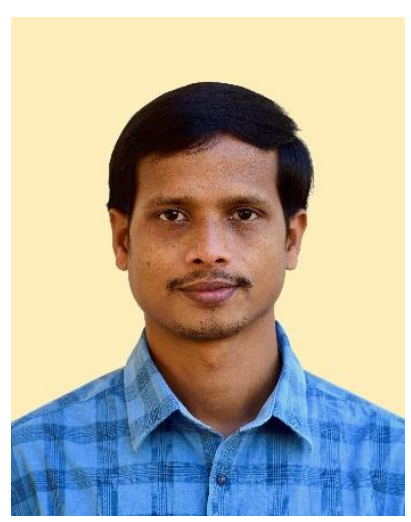

College, Utkal University, Odisha, and master's degree (2016) in Chemistry from the University of Hyderabad, Telangana. Currently, he is doing his Ph.D. under the guidance of Prof. Chivukula V. Sastri at the Indian Institute of Technology Guwahati. His field of work focuses on the impact of ligand architecture on regulating the electron transfer properties of metal-oxygen intermediates.

Jagnyesh Kumar Satpathy was born in Bahabal (Balangir), Odisha in 1996. Having graduated in 2016 from Rajendra (Auto)

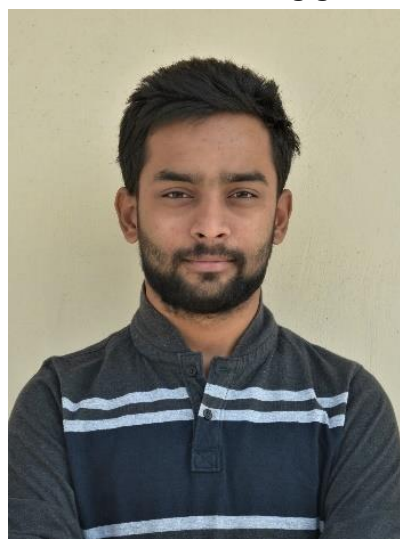
college, Balangir, Sambalpur University, he finished his M.Sc. degree in 2019 from the same university. Then, he moved to the Indian Institute of Technology Guwahati to pursue his Ph.D. under the supervision of Prof. Chivukula V. Sastri. He is doing his Ph.D. studies on the reactivity of high-valent nonheme metal-oxygen and metalnitrogen intermediates.

Gourab Mukherjee did his graduation (2012) and master's degree (2014) in Chemistry from the University of Burdwan, West Bengal, India. In 2019 he earned his Ph.D. in inorganic chemistry from the Indian Institute of Technology Guwahati under the mentorship of Prof. Chivukula V. Sastri. His work was

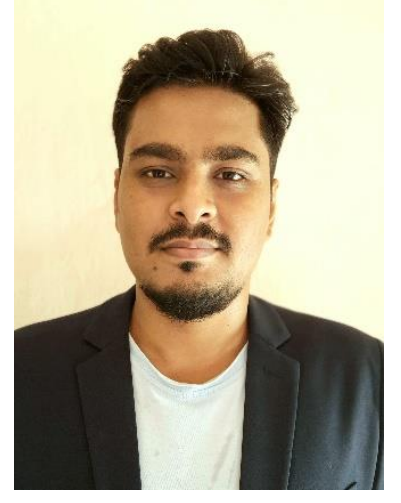

based on synthetic biomimetic model systems to activate dioxygen and hydrogen peroxide and study their reaction kinetics for mechanistic elucidations. Currently, he is a Research Associate at the Indian Institute of Technology Guwahati, working on synthetic alkyl and acyl-peroxo adducts of 3d-transition metal complexes.

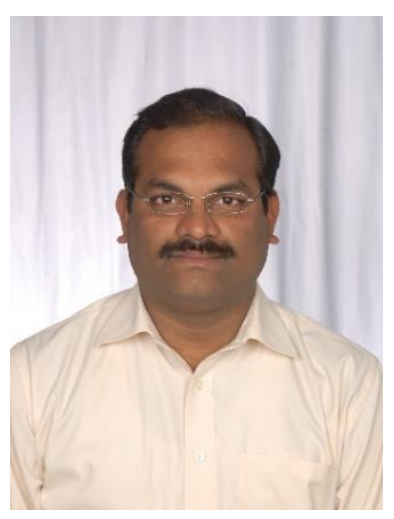

Chivukula V. Sastri was born in Hyderabad, India in 1975. He did his master's degree in Chemistry from Pune university in 1997 and obtained his Ph.D. in Chemistry under the supervision of Late Prof. B. G. Maiya from the University of Hyderabad in 2004. He was a PostDoctoral researcher in South Korea and the USA; and joined the Indian Institute of Technology Guwahati in 2008 as an Assistant Professor. Currently, he is a Professor in the Dept. of Chemistry, Indian Institute of Technology Guwahati. His research focusses on understanding the structure-function relationships and mechanistic aspects of high-valent non-heme metal intermediates.

Sam P. de Visser was born in the Netherlands and obtained an MSc and PhD in chemistry from the University of Amsterdam. After two postdoctoral positions (at King's College London and the Hebrew University of Jerusalem), he was appointed a lecturer position at the University of Manchester in 2004 and currently has the rank of Reader. His research interests are in computational modelling of metalloenzymes and biomimetic model complexes with particular focus on the catalytic reaction mechanisms of the cytochromes P450 and non-heme iron

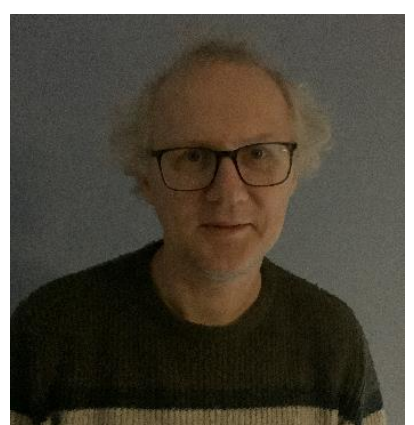
dioxygenases. 